EDUR • Educação em Revista. 2020; 36:e223426

DOI: http://dx.doi.org/10.1590/0102-4698223426

(9) (1) https://creativecommons.org/licenses/by/4.0/

ARTIGO

\title{
FATORES ASSOCIADOS À PERCEPÇÃO DE DIFICULDADE DA PROVA DO ENADE: UMA ANÁLISE A PARTIR DAS CARACTERÍSTICAS DOS ALUNOS E DAS INSTITUIÇÕES DE ENSINO SUPERIOR ${ }^{1}$
}

\author{
MARIA CAROLINA TOMÁS ${ }^{2}$ \\ ORCID: https://orcid.org/0000-0003-0811-4320 \\ LEONARDO SOUZA SILVEIRA ${ }^{3}$ \\ ORCID: https://orcid.org/ 0000-0002-9083-3123 \\ RAQUEL WANDERLEY D'ALBUQUERQUE ${ }^{4}$ \\ ORCID: https://orcid.org/0000-0002-6043-7613
}

\begin{abstract}
RESUMO: O artigo investiga a relação entre características do corpo discente e das instituições de ensino superior (IES) e a percepção dos estudantes quanto à dificuldade da prova do ENADE. A hipótese central é que essa percepção varia de acordo com características individuais, como sexo e raça, características socioeconômicas e características das IES. Analisam-se microdados do ENADE e do Censo do Ensino Superior, considerando-se apenas a prova de conteúdo geral para os cursos de Administração, Direito, Economia e Psicologia, em 2015. Os resultados apontam que características individuais são importantes para a percepção de dificuldade da prova e somente o percentual de professores com título de doutorado é significativo dentre as variáveis das IES.
\end{abstract}

Palavras-chave: Percepção de Dificuldade, ENADE, Ensino Superior.

\section{ASSOCIATED FACTORS TO ENADE'S PERCEPTION OF DIFFICULTY: AN ANALYSIS OF STUDENTS' AND HIGHER EDUCATION INSTITUTIONS' CHARACTERISTICS}

ABSTRACT: The article analyses the perception of the difficulty of the ENADE test and its relationship between the characteristics of the students and the higher education institutions (HEIs). The central hypothesis is that this perception varies according to individual characteristics, such as sex and race, socioeconomic characteristics, and Higher Education Institutions' characteristics. Microdata from ENADE and the Higher Education Census are analyzed in this article, considering only the general content test for Administration, Law, Economics, and Psychology courses in 2015. The results show that individual characteristics are relevant for the test difficulty perception, and the percentage of Professors with $\mathrm{PhD}$ degree is significant among the variables considered by the HEIs.

\footnotetext{
${ }^{1}$ Fundo de Incentivo à Pesquisa da PUC Minas - Projeto nº FIP 2017/302-S1

${ }^{2}$ Departamento de Ciências Sociais da Pontífica Universidade Católica de Minas Gerais. Belo horizonte, MG, Brasil. $<$ mctomas@pucminas.br>.

3 Pontifícia Universidade Católica de Minas Gerais (PUC-Minas). Belo Horizonte, MG, Brasil. $<$ leosilveira.soc@gmail.com>.

${ }^{4}$ Programa de Pós-Graduação em Ciência Política da Universidade Federal de Minas Gerais (UFMG). Belo horizonte, MG, Brasil.<raquel.dalbuquerque@gmail.com>.
} 
Key-words: Difficulty perception, ENADE, Higher Education.

\section{FACTORES ASOCIADOS A LA PERCEPCIÓN DE DIFICULTAD DE LA PRUEBA DEL ENADE: UN ANÁLISIS A PARTIR DE LAS CARACTERÍSTICAS DE LOS ESTUDIANTES Y DE LAS INSTITUCIONES DE EDUCACIÓN SUPERIOR}

RESUMÉN: El artículo investiga la relación entre las características del alumnado y de las instituciones de educación superior (IES) y la percepción de los estudiantes sobre la dificultad de la prueba del ENADE. La hipótesis central es que esta percepción varía según las características individuales, como el género y la raza, las características socioeconómicas y las características de las IES. Se analizan los microdatos del ENADE y el Censo de Educación Superior, considerando solo la prueba de contenido general para los cursos de Administración, Derecho, Economía y Psicología en 2015. Los resultados indican que las características individuales son importantes para la percepción de dificultad de la prueba y solo el porcentaje de professores com el titulo de doctor es significativo entre las variables consideradas de la IES.

Palabras clave: Percepción de Dificultad, ENADE, Enseñanza Superior.

\section{INTRODUÇÃO}

O contexto de avaliação do ensino superior, em especial os resultados do Exame Nacional de Desempenho dos Estudantes (ENADE), levanta questões para diferentes estudos. As análises, até o momento, têm focado no desempenho dos alunos, mas para melhor compreensão das desigualdades educacionais no Brasil há outras possíveis análises, como a percepção de dificuldade da prova. A percepção de dificuldade é tratada na literatura, principalmente pela psicologia social, como um fator ligado à ansiedade (BORG et al, 1970; BORG; FORSLING, 1964; HONG, 1999; WEBER; BIZER, 2006), mas ela pode também ser entendida como resultado de um processo de estratificação social, tendo em vista sua não aleatoriedade e sua concentração maior em alguns grupos, como negros, mulheres, alunos de instituições de mais baixo prestígio e alunos com níveis de renda mais baixos; refletindo processos sociais, como diferenças em oportunidades, expectativas, aspirações ou investimento na trajetória escolar. Dessa forma, pode-se afirmar que a percepção de dificuldade é uma função de atributos individuais e institucionais, resultado de um processo social.

Este trabalho tem como foco a análise da percepção de dificuldade da prova de conteúdo geral do ENADE para quatro cursos de graduação: Administração, Direito, Economia e Psicologia no ano de 2015. Para tanto, entende-se que essa percepção é influenciada por fatores individuais e pelas diferenças qualitativas do sistema educacional, refletidas pelas características das instituições de ensino às quais os estudantes estão vinculados. Estudar a percepção sobre a prova possibilita discutir quais 
fatores influenciam os alunos durante sua trajetória anterior e durante o ensino superior e oferecendo segurança no momento da prova, esses fatores podem ser entendidos como individuais e da instituição de ensino superior. Ademais, entender a configuração geral da percepção de dificuldade amplia o entendimento das desigualdades educacionais no ensino superior. Assim, trabalhamos com a hipótese de que estudantes com características individuais associadas a grupos socialmente privilegiados têm maior chance de considerar a prova fácil do que aqueles de grupos socialmente desprivilegiados, tais como pessoas negras, do sexo feminino e de níveis de renda mais baixos. Além disso, espera-se que a percepção da dificuldade sobre a prova seja maior entre estudantes vinculados a instituições de ensino cujas características refletem menor qualidade. Por outro lado, considera-se também que grupos que têm um desempenho pior na prova sejam aqueles que consideram-na mais fácil, de acordo com as análises de Bratfish (et al, 1972) e Borg (1966).

A avaliação do ensino superior, presente no Brasil há cerca de 20 anos, tem como principais objetivos acessar o nível de conhecimento de discentes de cursos de graduação e a qualidade das instituições. A criação do Exame Nacional de Cursos (ENC), popularmente conhecido como “Provão", em 1995, chegou a avaliar seis áreas do conhecimento até 2004 (VERHINE et al, 2006). Com a Lei n. 10.861/2004, instituiu-se o Sistema Nacional de Avaliação da Educação Superior (SINAES) cujo objetivo consiste em assegurar a avaliação das instituições de educação superior, dos cursos de graduação e do desempenho acadêmico de seus estudantes em nível nacional.

No âmbito do SINAES, ficou estabelecido o ENADE que passou a ser o principal instrumento de avaliação de discentes do ensino superior. De acordo com a lei mencionada, o Exame tem o objetivo de acessar o cumprimento de conteúdos programáticos estabelecidos pelas diretrizes curriculares de cada curso de graduação. Além disso, possibilita compreender as "habilidades para ajustamento [dos cursos] às exigências decorrentes da evolução do conhecimento e suas competências para compreender temas exteriores ao âmbito específico de sua profissão, ligados à realidade brasileira e mundial e a outras áreas do conhecimento" (BRASIL, 2004).

Nesse mesmo período e durante os anos seguintes, também é possível observar diversas mudanças quanto à expansão da rede e do acesso à educação superior. Isso se deu tanto pelo aumento do número de vagas em instituições de ensino da rede pública, quanto pela criação de programas de bolsas e financiamento governamentais para estudantes em instituições da rede privada ${ }^{5}$, além de ações

\footnotetext{
${ }^{5}$ Programa Universidade para Todos (Prouni) e Fundo de Financiamento Estudantil (Fies).
} 
afirmativas como a Lei de Cotas do Ensino Superior ${ }^{6}$. Essa expansão no acesso à educação superior trouxe diversas implicações, dentre elas a mudança e diversificação no perfil do corpo discente no que se referem a características econômicas, sociais, étnico-raciais e de gênero.

Alguns estudos (TELLES; MARINHO, 2014; BRITO, 2015; CARMO; ALMEIDA, 2015; CREPALDE; SILVEIRA, 2016; RODRIGUES et al, 2017) apontam que as características dos alunos influenciam seu desempenho no ENADE e que as caraterísticas das instituições onde estudam são igualmente importantes. Por exemplo, Rodrigues et al (2017) apontam diferenças significativas em todas as médias obtidas na prova de acordo com sexo, nível socioeconômico e tipo de organização, categoria administrativa da instituição e modalidade do curso de discentes concluintes nas edições do ENADE de 2006, 2009 e 2012. Juntamente com a literatura sobre acesso e chances de conclusão do ensino superior, esses resultados levam à argumentação em favor de análises que contemplem fatores socioeconômicos, raciais e sexo dos estudantes, assim como a diferença qualitativa das instituições de ensino, para compreender a percepção de dificuldade da prova do ENADE, entendo esse fenômeno como resultado de processos sociais.

Para a análise, foram utilizados dados do Instituto Nacional de Estudos e Pesquisas Educacionais Anísio Teixeira (INEP) referentes ao ENADE, para cursos com diferentes composições de estudantes, no ano de 2015. Utilizam-se também dados do Censo da Educação Superior para complementar as informações referentes à composição do corpo docente (como percentual daqueles que possuem doutorado). As informações foram analisadas por meio de técnicas estatísticas descritivas e inferenciais, além de modelos hierárquicos lineares e logísticos.

Os resultados apontam que características individuais são importantes para compreensão da percepção do nível de dificuldade da prova de conteúdo geral e que apenas o percentual de docentes doutores é significativo dentre as variáveis das IES analisadas. O trabalho se divide em cinco seções para além desta introdução. Na segunda seção, faz-se uma breve contextualização das desigualdades no ensino superior em associação ao fenômeno da expansão para, na seção seguinte, serem abordadas as orientações teóricas que baseiam as hipóteses de pesquisa do trabalho. Em seguida, os procedimentos de análise dos dados são esclarecidos e, então, apresentam-se os resultados. Por fim, apresentam-se as contribuições teórico-analíticas do trabalho tecendo as considerações finais.

\section{EXPANSÃO DO ENSINO SUPERIOR NO CONTEXTO DAS DESIGUALDADES}

${ }^{6}$ Lei no 12.711 de 2012: http://www.planalto.gov.br/ccivil_03/_ato2011-2014/2012/lei/112711.htm 
O ensino superior é tratado como um pilar importante de desenvolvimento econômico, político, cultural e sociológico das sociedades modernas (JARUSCH, 1983). Trata-se de qualificar a população em termos produtivos e culturais, e um meio de equalizar oportunidades. Do ponto de vista da análise de desigualdades, porém, o sistema educacional apresenta nuances que devem ser observadas. Experiências internacionais demonstram que expansões foram feitas privilegiando ora aspectos mais competitivos, ora aspectos mais igualitários.

Diferentes escolhas institucionais definem o caráter da expansão do sistema de ensino superior (MARTINS, 2013). Dubet (2015) demonstra que essas diferenciações são sutis, e podem ser contraditórias, como, por exemplo, o fato de massificação não significar democratização. Isto é, assim como diversos bens de consumo se massificaram e passaram a ser acessados por diversos estratos sociais, o mesmo ocorre com o acesso a esse nível de ensino - não garantindo, necessariamente, justiça ou equidade. O problema da massificação, porém, é sua incorporação de desigualdades não sanadas previamente, como, por exemplo, a posse dos capitais humano, social e cultural, que facilitam a apropriação dos ativos proporcionados pela educação por grupos dominantes (BOURDIEU, 2011). Desse modo, em um cenário de maior incorporação de alunos em determinado nível escolar, incorporam-se também desigualdades prévias àquela etapa. Segundo Dubet (2015), cria-se uma democratização segregada, com hierarquizações por prestígio de cursos, categorias administrativas e acadêmicas, que continuam tendo papel importante na reprodução das elites em seus determinados países.

O Brasil possui seus desafios próprios no que concerne à expansão do ensino superior. De maneira geral, o país permanece com baixa taxa de escolarização líquida, se comparado com países vizinhos da América Latina (TACHIBANA et al, 2015), sendo o gargalo do Ensino Médio um dos fatores para tal, porém, não o único. Nesse nível, a evasão é elevada e a taxa de escolarização líquida baixa, uma vez que metade dos jovens entre 15 e 17 anos estão fora dessa etapa escolar (UNESCO, 2012). As defasagens se tornam ainda mais evidentes nos recortes por raça, gênero e grupo socioeconômico.

Por raça, o grupo negro enfrenta rígidas barreiras e, consequentemente, sub-representação no nível terciário de escolarização (SILVA; HANSENBALG, 2000; RIBEIRO, 2006; FERNANDES, 2005). Contrastando edições do censo demográfico, negros compunham 5\%, 8\% e 10\% dos graduados em arquitetura, engenharia e pedagogia em 1980, respectivamente. Em 2010, os valores se alteram para 
$12 \%, 17 \%$ e $34 \%{ }^{7}$. Isto é, mesmo com o aumento de sua participação no ensino superior, esse grupo ainda é subrepresentado, e sua participação varia com relação ao curso.

Por outro lado, a combinação de expansão do número de vagas com a adoção de ações afirmativas parece ter influenciado o acesso desse grupo ao ensino superior (OLIVEIRA; SILVA, 2017). Segundo Marteleto (et al, 2016), a influência da escolaridade dos pais tem se mantido relevante para explicar o acesso, ao contrário da variável raça que tem diminuído sua influência. Nesse sentido, as probabilidades têm se tornado mais equitativas, apesar de ressalvas feitas pelos autores, de que: (i) o gargalo da conclusão do Ensino Médio é persistente e penaliza principalmente os negros, demonstrando uma limitação do investimento apenas no nível mais alto de ensino; (ii) os dados analisados possuem limitações, uma vez que não é possível medir a variação por tipo de curso em que grupos brancos e negros estão se inserindo, nem sua permanência no curso superior.

O recorte socioeconômico também apresenta heterogeneidades no cenário de expansão do Brasil. Como apresentado por Marteleto (et al, 2016), a origem socioeconômica segue como importante preditora para o acesso, principalmente, daqueles filhos de pais com ensino superior completo. Contudo, é importante destacar que há mudanças devido às ações afirmativas. Amaral (et al, 2012) demonstram que a adoção do bônus socioeconômico ${ }^{8}$ pela Universidade Federal de Minas Gerais (UFMG) teve efeito nunca visto anteriormente na composição de cursos considerados “de elite". Isto é, em cursos menos concorridos, como Administração e Química, o percentual de alunos de escolas públicas era variável e, até mesmo, representativo ao longo dos anos. Porém, em cursos como Medicina e Direito, somente após a adoção do bônus, esses alunos passaram a compor uma parte do corpo discente, ainda que pequena (AMARAL et al, 2012). Isso demonstra que a importância de ações mitigadoras de desigualdade depende de qual recorte é observado, variando, por exemplo, segundo a área, o curso e seu prestígio.

A área de concentração do curso e seu prestígio também têm importante ressonância para o recorte por gênero. A distribuição de mulheres frequentando cursos de graduação é superior à de homens, sendo que essas representavam 57\% dos estudantes do nível terciário em 2010 (RICOLDI; ARTES, 2016). Porém, a inserção das mulheres é segmentada por área de conhecimento, estando

\footnotetext{
${ }^{7}$ Esses dados foram acessados pelos próprios autores por meio de manipulação dos microdados do censo demográfico brasileiro 1980 e 2010 .

${ }^{8} \mathrm{O}$ bônus socioeconômico foi uma medida adotada a partir do vestibular de 2009 na UFMG pelo qual estudantes inscritos como autoclassificação preta, parda ou indígena e provenientes de escolas públicas tinham um acréscimo de até $15 \%$ na pontuação final.
} 
matriculadas, principalmente, em cursos das áreas de saúde e pedagogia, que são áreas relacionadas ao cuidado?. Ao analisar os dados de 1980 e 2010 para pedagogia, arquitetura e engenharia civil, observa-se que as mulheres continuam predominando nos dois primeiros cursos e aumentam seu acesso lentamente no terceiro. Em 1980, as mulheres eram 39\% dos alunos no curso de arquitetura, 91\% em pedagogia, e $6 \%$ no curso de engenharia civil. Trinta anos depois, os valores são de 59\%, 83\% e 16\%, respectivamente. Segundo Ricoldi e Artes (2016), o aumento do percentual de mulheres em ocupações “tipicamente masculinas” é lento, bem como o inverso também é verdadeiro (homens em ocupações de educação e cuidado). Assim, mesmo sendo maioria no ensino superior, as mulheres nem sempre ocupam proporcionalmente cursos mais prestigiosos, afetando sua ocupação em posições de poder e seu retorno salarial, já reduzido pela discriminação.

Esses efeitos sobre raça, gênero e grupos socioeconômicos refletem alguns aspectos acerca da expansão do ensino superior e suas variações nas chances de acesso, bem como formas de diferenciação interna ao ensino superior. No que diz respeito à expansão, o Brasil lida com aspectos relacionados à hipótese MMI (Maximally Maintened Inequality) ou "hipótese da desigualdade maximamente mantida" (RAFTERY; HOUT, 1993). Por essa, compreende-se que grupos subalternos só acessam etapas mais elevadas de escolaridade quando os grupos privilegiados já se encontram totalmente inseridos nelas. Assim, grupos socioeconômicos com renda e escolaridade mais baixas passam a acessar o ensino superior apenas a partir do momento em que os privilegiados estão completamente inseridos e bem posicionados dentro do mesmo.

Para além do acesso, a origem socioeconômica se associa à permanência no ensino superior. Como demonstram Mendes e Costa (2015), mesmo após o acesso, as características familiares, como recursos econômicos e o capital cultural, representado pela frequência a museus, exposições, bibliotecas, entre outras, são significativos para a permanência dos jovens entre 18 e 24 anos nesse nível de ensino.

O Brasil traz, portanto, um cenário de mudanças recentes, com o aumento no número de matrículas de 1,5 milhão para 6 milhões entre 1995 e 2015 (INSTITUTO NACIONAL DE ESTUDOS E PESQUISAS ANÍSIO TEIXEIRA, 1995; 2015). Contudo, há evidências e hipóteses que apontam para limitações no que diz respeito à democratização do nível superior, sendo essa,

\footnotetext{
${ }^{9} \mathrm{Na}$ naturalização dos papeis sociais de gênero, atribui-se e reforça-se sobre as mulheres uma função de cuidadora do lar. Isso acaba extrapolando os limites domésticos, e se reflete no mercado de trabalho, como se esse papel de cuidadora fosse intrínseco à condição feminina (SANTOS, 2014).
} 
segregativa, nos termos de Dubet (2015). De maneira geral, permanecem questionamentos sobre a desigualdade no ensino superior.

\section{CAMINHOS PARA COMPREENDER A PERCEPÇÃO DE DIFICULDADE: ACESSO, DESEMPENHO E CONCLUSÃO DO ENSINO SUPERIOR}

Muitas são as formas de expressão das desigualdades no ensino superior. Logo, existem diferentes perspectivas que permitem a análise de como estas desigualdades afetam os indivíduos: seja por meio de diferentes condições para acesso, seja na escolha de cursos associada ao retorno financeiro e status social, seja no desempenho dos estudantes ao longo da graduação ou na construção de uma percepção de dificuldade em relação a exames de proficiência. Todos esses fatores são amplamente estudados no âmbito da sociologia, com exceção para o último: a percepção de dificuldade em relação a exames de proficiência no ensino superior tem sido tratada principalmente pela psicologia social.

Percepção de dificuldade é frequentemente relacionada à ansiedade para realização de uma prova e tem sido analisada de diferentes maneiras, seja através de anúncio de que a prova é difícil (WEBER; BIZER, 2006), por meio de um teste antes da prova, ou da percepção dos alunos durante a prova (HONG, 1999). A ideia de mensurar a percepção de dificuldade aparece incialmente em Borg (1961), e os primeiros estudos que se seguiram focaram principalmente na relação da percepção de dificuldade com a realização de exercícios físicos, principalmente, em três aspectos: i) indicadores de percepção de estresse e dificuldade; ii) indicadores fisiológicos; e iii) indicadores de performance. De maneira geral, a tentativa foi de compreender em que medida a percepção de dificuldade poderia ser considerada um fenômeno independente e o quanto seria influenciada por diferentes fatores (BORG et al, 1971). Posteriormente, outros estudos utilizaram experimentos para compreender a percepção de dificuldade em testes e habilidades mentais e intelectuais (como BORG; FORSLING, 1964).

No caso da percepção de dificuldade sobre a prova do ENADE, a medida utilizada se refere a uma questão que o aluno responde ao final da prova, ou seja, corresponde à percepção que o aluno teve ao longo da prova e é formalizada ao final. Pode-se, portanto, defini-la como Delignières (1999), uma avaliação subjetiva do que é exigido para realizar uma tarefa. Para entender o que a determina, algumas investigações analisaram seus determinantes e mostraram uma relativa independência entre a dificuldade percebida e os resultados alcançados. Em outras palavras, um sujeito poderia avaliar uma tarefa como fácil, mesmo sem obter resultados satisfatórios ou avaliar a tarefa como difícil, apesar de um bom desempenho. Dessa maneira, a percepção reflete a quantidade de recursos investidos na tarefa. Então, quando um aluno diz "essa é uma tarefa é difícil" significa, 
principalmente, que ele ou ela trabalhou muito para realizá-la. Embora o contexto de análise de Delignières (1999) seja o das atividades motoras, o mesmo pode ser estendido às atividades mentais.

Bratfish (et al, 1972), por outro lado, interessados na construção de itens para testes, realizaram um experimento e encontraram alta correlação $(r=0,90)$ entre a ordem de classificação dos itens e a dificuldade percebida pelos alunos. Além disso, o aumento relativo da dificuldade percebida foi mais pronunciado para indivíduos com uma pontuação de alto desempenho no teste do que para indivíduos com uma baixa pontuação de desempenho. Um fator levantado pelos autores é que os piores alunos não entendiam completamente o que estavam avaliando, já que a capacidade de estimar a dificuldade das tarefas depende da capacidade de resolvê-las adequadamente. Os autores ainda citam Borg (1966) que conclui que uma pessoa com menor habilidade parece achar mais fácil aceitar uma solução errada e, portanto, considera a tarefa relativamente mais fácil (BORG, 1966 apud BRATFISH et al, 1972).

A partir dos diferentes resultados, argumentamos, neste trabalho que, se fatores socioeconômicos são relevantes na determinação do acesso, desempenho e conclusão no ensino superior, faz-se necessário contabilizá-los na composição da percepção de dificuldade dos estudantes. Isso porque as chances de um estudante ter acesso, atingir determinado desempenho e concluir ou desistir de um curso de ensino superior não dependem apenas de sua vontade, suas escolhas, sua inteligência ou estado emocional, mas de um conjunto de fatores sociais que marcam toda sua trajetória escolar. Da mesma forma, fatores como renda, raça e sexo dos alunos também têm o potencial de afetar a percepção que eles têm sobre a dificuldade de provas de proficiência. Portanto, para além de elementos psicossociais (notadamente, a ansiedade na hora da prova), a percepção de dificuldade deve ser compreendida em associação a fatores sociais, pois se trata de uma questão que extrapola o nível individual. Além disso, a relação inversa entre desempenho e percepção de dificuldade da prova aponta para a necessidade de análises desses dois fenômenos independentemente.

Os estudos sobre as desigualdades de oportunidades de acesso ao ensino superior tendem a abordar a sub-representação de alguns grupos e a sobrerrepresentação de outros, segundo aspectos socioeconômicos, étnico-raciais e de gênero (PICANÇO, 2015; CARVALHO; WALTENBERG, 2015; JEZINE, 2016; GISI, 2006; OLIVEIRA; SILVA, 2017; RIBEIRO, 2016). Ribeiro (2011) analisa o sistema educacional brasileiro como um todo e destaca a importância de um olhar que leve em conta as características individuais e familiares dos estudantes em associação às características do próprio sistema (como das instituições de ensino) para compreender as chances de progressão em todas as etapas da vida escolar: do ensino fundamental ao ensino superior. $O$ autor argumenta que tanto recursos 
familiares quanto estruturais afetam a reprodução ou superação das desigualdades de oportunidades e de resultados educacionais em todos os níveis de ensino.

No ensino superior, é possível compreender a estratificação horizontal ao analisar as escolhas dos cursos pelos estudantes levando-se em consideração as possibilidades de retornos econômicos e de status social associados aos cursos escolhidos, o que depende de fatores sociais como classe, sexo e raça, como destacado na seção anterior. Ressalta-se que, apesar da expansão do acesso de pretos e pardos ao ensino superior em função de políticas de inclusão como cotas e ação afirmativa, ainda há grande desigualdade racial nesse sistema educacional. Persiste a sobrerrepresentação de pessoas brancas nos cursos considerados de mais alto retorno socioeconômico e status social. De forma semelhante, estudantes de nível socioeconômico mais alto ocupam as vagas dos cursos de maior retorno e status; da mesma maneira, homens estão majoritariamente presentes em cursos de maior retorno econômico enquanto mulheres ocupam vagas em cursos de menor retorno, normalmente em cursos relacionados à docência ou a cuidados de saúde. Ou seja: os cursos considerados de alto retorno econômico e status social são ocupados majoritariamente por pessoas brancas, de renda mais alta e do sexo masculino (CARVALHAES; RIBEIRO, 2019).

No que se refere aos estudos acerca da influência de fatores socioeconômicos sobre a escolarização, Sewell e Shaha (1967) ressaltam que, desde seus antecessores, é possível encontrar uma forte relação entre acesso, desempenho e conclusão em diferentes níveis de escolarização e status socioeconômicos dos estudantes no contexto estadunidense. Os autores destacam o grande número de estudos que demonstram a existência de uma baixa probabilidade de acesso ao ensino superior por estudantes que sejam de status socioeconômicos mais baixos, do sexo feminino ou membros de grupos raciais em desvantagens sociais, mesmo que esses estudantes tenham alta capacidade intelectual comprovada. Os autores analisam (i) o status socioeconômico operacionalizado como escolaridade e ocupação formal dos pais, renda familiar e nível de sacrifício que seria para a família mandar o filho para a faculdade, além de uma (ii) medida de "inteligência", e (iii) sexo, em uma coorte de estudantes recém concluintes do ensino médio nos Estados Unidos, de 1957 a 1964.

Os resultados das análises mostraram que tanto status socioeconômico quanto a inteligência estão relacionados com acesso ${ }^{10}$, comparecimento e conclusão do nível superior entre homens e mulheres. De modo geral, para qualquer nível de inteligência mensurado (baixo, médio ou alto), quanto maior o status socioeconômico, maiores são as chances de acesso, continuidade e

\footnotetext{
${ }^{10}$ Ressalta-se que o "acesso" analisado pelos autores diz respeito ao "college planning”, ou seja, ao fato de o estudante ter um planejamento de ingressar no nível superior que é essencialmente privado nos Estados Unidos.
} 
conclusão do ensino superior. Quando são analisados apenas os estudantes que, de fato, ingressaram no ensino superior, o efeito do status socioeconômico fica ainda mais claro: apesar de haver um filtro social e econômico no próprio fato de ingressar no ensino superior, as maiores chances de conclusão desse nível de ensino estão entre os estudantes (homens ou mulheres) pertencentes a grupos com maiores status.

Retomando o caso brasileiro, Ribeiro (2011) realiza uma análise temporal e verifica que o efeito da ocupação do pai do indivíduo (variável que indica o nível de renda permanente do pai) diminui progressivamente ao longo do percurso educacional do ensino fundamental ao ensino médio. Porém, quando se trata de acessar o ensino superior e, principalmente, de conclui-lo, esse se mostra como um fator de maior importância. Segundo o autor, mesmo para os estudantes que já acessaram o ensino superior, o nível de riqueza dos pais ${ }^{11}$ é um fator determinante nas chances de sucesso nessa etapa de transição educacional. "Ou seja, a desigualdade de oportunidades em termos de riqueza permanece presente até a última transição do sistema educacional, momento em que a grande maioria dos outros tipos de desigualdade não existe mais" (p. 60). Além disso, o autor verifica que estudantes brancos têm até 1,5 vezes mais chances de acessar e concluir o ensino superior do que estudantes pardos.

Conjuntamente a fatores ligados à renda dos estudantes, Crepalde e Silveira (2016) exploram a relação entre cor/raça e sexo dos estudantes com o desempenho alcançado na prova do ENADE, para diferentes cursos. De modo geral, os resultados apontam que estudantes negros têm nota média 1,1 pontos menores em relação à nota de estudantes brancos, enquanto estudantes do sexo masculino apresentam, em média, notas 0,7 pontos menores do que de estudantes do sexo feminino. Quanto às condições financeiras, verificou-se que conforme a renda familiar aumenta, também aumenta o desempenho dos estudantes. Por fim, os autores destacam a existência de diferenças nos resultados quando considerados os cursos separadamente e também quando considerada a categoria administrativa da instituição de ensino superior (se pública ou privada).

A literatura sobre o tema nos permite identificar chances distintas entre homens e mulheres, negros e brancos e alunos de diferentes níveis de renda (i) para acessar ou não a universidade, (ii) para escolher cursos de graduação, e (iii) para concluir o ensino superior. Sabe-se também que essas chances são influenciadas por fatores que vão além de preferências e escolhas individuais, pois esses processos são perpassados por diferentes formas de desigualdade. Sendo assim, defendemos a

\footnotetext{
11 "Esta riqueza não é propriamente representada pela renda ou pelo status ocupacional, mas, sim, pelos bens e ativos que os pais possuíam, ou seja, é uma dimensão distinta das desigualdades socioeconômicas” (RIBEIRO, 2011, p; 60).
} 
necessidade de analisar estes fatores para compreender a percepção de dificuldade que os estudantes têm sobre as provas do ENADE, pois entendemos que essa percepção, assim como a escolha por cursos e o desempenho, não depende unicamente da ansiedade ou das habilidades dos estudantes, mas é resultado de uma construção social.

Por fim, como se trata de um sistema de educação superior e não somente da perspectiva individual dos estudantes, cabe também destacar as condições em que esse processo de aprendizado se desenvolve. Dito de outro modo: faz-se necessário analisar as características das instituições de ensino e sua influência sobre a percepção de dificuldade dos estudantes. Isso porque, assim como os cursos, as instituições de ensino superior carregam diferenças qualitativas do sistema educacional através de diferentes formas de organização acadêmica e também de categorias administrativas (CARVALHAES; RIBEIRO, 2019).

Cabe aqui destacar que quanto maior o nível socioeconômico dos estudantes, menor a chance de ocuparem o ensino privado, isto é, as instituições de ensino superior públicas são ocupadas sistematicamente por estudantes de nível socioeconômico mais alto, quanto que o setor privado absorve aqueles de origem socioeconômica mais baixa, segundo Carvalhaes e Ribeiro (2019). Ainda segundo os autores:

[...] [os] modelos institucionais dos setores de oferta público e privada têm, explicitamente, direções distintas com características organizacionais próprias, notadamente o ensino e a pesquisa. Institucionalmente isso é explicitamente adotado no turno de oferta de cursos (diurno, vespertino ou noturno) que, naturalmente, afeta o tipo de público que frequenta cada setor e, consequentemente, a composição socioeconômica dos alunos dos cursos. Como há mais cursos noturnos no setor privado, essa pode ser uma das razões de vermos a absorção de estudantes de nível socioeconômico baixo no setor (p. 2018).

Sendo assim, a importância de se considerar também as características das instituições de ensino se justifica pelo chamado efeito escola ${ }^{12}$, destacado pela literatura, que considera tanto as características administrativas e de infraestrutura quanto a composição do corpo docente. No que se refere ao desempenho dos estudantes no ENADE, a diferenciação por instituição de ensino tem um efeito atenuador na dimensão das desigualdades de gênero, raça e renda familiar. Isso porque, quando inserida a identificação da instituição de ensino como pública ou privada, esse fator se sobressai às características individuais na determinação do desempenho dos estudantes. Isso implica dizer que "a

12 “Conforme a literatura acerca do 'efeito escola' aponta, o ambiente escolar tem influência em diversos aspectos, inclusive no desempenho (SOARES, 2003). Desse modo, ao estudar o desempenho do alunado, a instituição se torna também uma variável de interesse, e não somente a heterogeneidade entre os indivíduos” (CREPALDE; SILVEIRA, 2016, p. 213). 
escola tem um efeito que ultrapassa as diferenças sexo, cor ou renda familiar" (CREPALDE; SILVEIRA, 2016, p. 230).

Ainda acerca da categoria administrativa da IES, Rowe e Bastos (2010) destacam uma importante diferença: em instituições públicas, há uma forte correlação positiva entre, de um lado, a obtenção de incentivos como bolsa de produtividade científica, coordenação de projeto de pesquisa e orientação de mestrandos e doutorandos e, do outro lado, a produção de docentes em termos de publicações em periódicos, participação e publicações em anais de eventos acadêmicos. O mesmo não ocorre quando são analisadas as instituições privadas.

Em uma direção semelhante, os resultados das análises realizadas por Telles e Marinho (2014) apontam que discentes de instituições públicas apresentam melhor desempenho no ENADE. Os autores também analisam o tipo de organização acadêmica das instituições e concluem que discentes vinculados a instituições classificadas como centros universitários e faculdades têm desempenho inferior àqueles vinculados a universidades. Além disso, os resultados encontrados por Lemos e Miranda (2015) apontam que a qualificação do corpo docente, em termos dedicação, titulação e formação pedagógica, assim como as condições de infraestrutura, têm efeitos substanciais sobre o desempenho dos estudantes no ENADE.

Tendo em vista a importância das características das IES para explicar o desempenho dos alunos, espera-se que esses fatores também influenciem sua percepção de dificuldade da prova. É possível compreender, portanto, que além da categoria administrativa da instituição de ensino superior, é importante levar em conta fatores como tipo de organização acadêmica e composição do corpo docente. Acredita-se que, ao incorporar tais características às análises, ampliam-se os fatores organizacionais, o que leva ao melhor entendimento sobre o papel das IES sobre o processo educacional em termos de percepção de dificuldade dos estudantes.

\section{DADOS E MÉTODOS}

Os dados analisados foram produzidos pelo Instituto Nacional de Estudos e Pesquisas Educacionais Anísio Teixeira (INEP) e correspondem às informações sobre os estudantes que prestaram a prova do ENADE, assim como às informações das instituições presentes no Censo do Ensino Superior, ambos para o ano de 2015. Nesse ano, os estudantes que participaram do exame foram os concluintes de 26 cursos de bacharelado e tecnólogo. Todos eles foram submetidos à mesma prova de conteúdo geral, possibilitando a comparação entre todos os estudantes para a análise da 
percepção de dificuldade de uma mesma prova. Vale ressaltar que, de todo modo, a análise é realizada separadamente por curso.

A seleção dos cursos levou em consideração a distribuição do corpo discente por sexo, a fim de se garantir diferentes cenários para a discussão e, por fim, quatro cursos foram selecionados: Administração, Direito, Economia e Psicologia. O curso de Psicologia é composto majoritariamente por mulheres, enquanto os cursos de Administração e Direito têm maior equilíbrio quanto à distribuição por sexo. Além disso, o curso de Economia, dentre os que realizaram o ENADE em 2015, é o terceiro curso com maior proporção de homens, atrás de Teologia e Tecnologia de Logística - que são cursos cujas dinâmicas são muito distintas dos demais. Para a análise, foram consideradas as variáveis e as hipóteses apresentadas no Quadro 1.

A análise dos dados se divide em duas etapas. A primeira tem como objetivo explorar e descrever as características dos estudantes e das IES de forma geral e também os níveis de percepção de dificuldade da prova. Esaa primeira parte proporciona conhecer melhor o grupo de indivíduos e instituições selecionados para a análise e oferece indícios de tendências gerais, permitindo algumas inferências descritivas, nos termos de King (et al, 1994). Já na segunda etapa da análise, parte-se para a modelagem dos dados com o objetivo de atingir maiores níveis de controle sobre as variáveis e identificar o grau de associação destas características com a probabilidade de estudantes considerarem a prova difícil ou não, e sua significância. Busca-se, portanto, explicações para a variação da percepção de dificuldade na prova do ENADE para cada um dos quatro cursos selecionados.

Desse modo, modelos hierárquicos (ou multiníveis) são fundamentais para a análise desenvolvida, uma vez que consideram simultaneamente tanto as associações no menor nível (individual), quanto em nível agregado (instituição). Para analisar a percepção do nível de dificuldade da prova (variável categórica) utilizou-se um modelo multinível logístico. Além disso, é importante considerar possíveis relações entre variáveis independentes. Por exemplo, mulheres brancas e mulheres negras podem enfrentar obstáculos, como discriminação ou diferenças no processo de socialização, que não dizem apenas respeito à raça ou ao sexo, mas a uma combinação desses fatores. Logo, faz-se necessário o uso de termos interativos de raça e sexo do respondente, que demonstram especificidades em suas combinações.

\section{QUADRO 1}

Variáveis, Mensuração e Hipóteses

\begin{tabular}{|c|c|c|}
\hline Variável & as/Mensuração & Relação Es \\
\hline $\begin{array}{l}\text { Percepção } \\
\text { dificuldade } \\
\text { prova }\end{array}$ & $\begin{array}{l}\text { 1= Difícil (inclui as categorias: Muito } \\
\text { Difícil e Difícil) } \\
0=\text { Não Difícil (inclui as categorias: Fácil } \\
\text { e Médio) }\end{array}$ & $\begin{array}{l}\text { A percepção dos estudantes quanto à } \\
\text { dificuldade da prova do ENADE varia de } \\
\text { acordo com características individuais e } \\
\text { características das IES }\end{array}$ \\
\hline
\end{tabular}

Educação em Revista|Belo Horizonte|v.36|e223426|2020 


\begin{tabular}{|c|c|c|}
\hline \multicolumn{3}{|c|}{ Nível 1: Características dos Estudantes } \\
\hline Sexo & $\begin{array}{l}0=\text { Feminino } \\
1=\text { Masculino }\end{array}$ & $\begin{array}{l}\text { Estudantes do sexo feminino têm maior } \\
\text { chance de considerar a prova difícil }\end{array}$ \\
\hline Cor/raça ${ }^{13}$ & $\begin{array}{l}0=\text { Não-Branca (Parda e Negra) } \\
1=\text { Branca }\end{array}$ & $\begin{array}{l}\text { Estudantes negros têm maior chance de } \\
\text { considerar a prova difícil }\end{array}$ \\
\hline Renda & $\begin{array}{l}1=\text { Até } 1,5 \text { salário mínimo } \\
2=\text { De } 1,5 \text { até } 3 \text { salários mínimos } \\
3=\text { De } 3 \text { até } 4,5 \text { salários mínimos } \\
4=\text { De } 4,5 \text { até } 6 \text { salários mínimos } \\
5=\text { De } 6 \text { até } 10 \text { salários mínimos } \\
6=\text { De } 10 \text { até } 30 \text { salários mínimos } \\
7=\text { Acima de } 30 \text { salários mínimos }\end{array}$ & $\begin{array}{l}\text { Estudantes em menores faixas de renda têm } \\
\text { maior chance de considerar a prova difícil }\end{array}$ \\
\hline Idade & Em anos & \multirow{7}{*}{ Controle } \\
\hline Estado civil & $\begin{array}{l}0=\text { Não Solteiro } \\
1=\text { Solteiro }\end{array}$ & \\
\hline Trabalho & $\begin{array}{l}0=\text { Não trabalha } \\
1=\text { Trabalha até } 20 \mathrm{~h} \text { semanais } \\
2=\text { Trabalha acima de } 20 \mathrm{~h} \text { semanais }\end{array}$ & \\
\hline Bolsa & $\begin{array}{l}0=\text { Curso gratuito } \\
1=\text { Curso pago } \\
2=\text { Curso pago com algum tipo de bolsa }\end{array}$ & \\
\hline Auxílio & $\begin{array}{l}0=\text { Não recebe auxílio } \\
1=\text { Recebe algum auxílio (moradia, } \\
\text { alimentação, permanência ou outro) }\end{array}$ & \\
\hline Ação Afirmativa & $\begin{array}{l}0=\text { Ingresso sem ação afirmativa } \\
1=\text { Ingresso com ação afirmativa }\end{array}$ & \\
\hline Ensino Médio & $\begin{array}{l}0=\text { Ensino Médio em instituição privada } \\
1=\text { Ensino Médio em instituição pública }\end{array}$ & \\
\hline \multicolumn{3}{|c|}{ Nível 2: Características das IES } \\
\hline Corpo Docente & Proporção de Docentes Doutores & \begin{tabular}{|l} 
Estudantes de instituições cujo corpo \\
docente tem menor proporção de \\
professores doutores têm maior chance de \\
considerar a prova difícil
\end{tabular} \\
\hline $\begin{array}{l}\text { Categoria } \\
\text { Administrativa }\end{array}$ & $\begin{array}{l}1=\text { Pública Federal } \\
2=\text { Pública Estadual } \\
3=\text { Pública Municipal } \\
4=\text { Privada }\end{array}$ & $\begin{array}{l}\text { Estudantes de instituições privadas têm } \\
\text { maior chance de considerar a prova difícil }\end{array}$ \\
\hline $\begin{array}{l}\text { Organização } \\
\text { Acadêmica }\end{array}$ & $\begin{array}{l}1=\text { IF e CEFET } \\
2=\text { Centro Universitário/Faculdade } \\
3=\text { Universidade }\end{array}$ & $\begin{array}{l}\text { Estudantes de universidades têm menor } \\
\text { chance de considerar a prova difícil }\end{array}$ \\
\hline Região & $\begin{array}{l}1=\text { Norte } \\
2=\text { Nordeste } \\
3=\text { Sudeste } \\
4=\text { Sul } \\
5=\text { Centro-Oeste }\end{array}$ & \multirow[t]{3}{*}{ Controle } \\
\hline Turno & $\begin{array}{l}1=\text { Matutino } \\
2=\text { Vespertino } \\
3=\text { Noturno }\end{array}$ & \\
\hline Curso & $\begin{array}{l}\text { Administração, Direito, Economia ou } \\
\text { Psicologia }\end{array}$ & \\
\hline
\end{tabular}

13 As opções disponíveis no ENADE são branca, negra, parda, asiática e indígena. Foram utilizadas apenas as três primeiras. 


\section{RESULTADOS}

As análises descritivas das características de todos os indivíduos presentes no grupo de estudantes analisado estão sumarizadas nas TAB. 1 a 5, presentes no Apêndice deste artigo. O grupo de estudantes concluintes que realizaram ENADE nos cursos de Administração, Direito, Economia e Psicologia, em 2015, é composto majoritariamente por mulheres, pessoas brancas, solteiras e que trabalham acima de 20 horas semanais. Quanto à renda domiciliar per capta, temos 53,4\% de estudantes que se concentram no espectro de 1,5 a 4,5 salários mínimos. A maior parte dos estudantes $(88,5 \%)$ está vinculada a instituições privadas ou recebe algum tipo de bolsa. Os concluintes analisados, em geral (95,9\%), não recebem auxílio (auxílio moradia, alimentação, permanência ou outro) e, em sua maioria, não ingressaram por meio de ações afirmativas, o que faz sentido considerando que mais de $60 \%$ tenham cursado ensino médio em instituições privadas (TAB. 1, APÊNDICE A).

No que se refere aos cursos separadamente, predomina o corpo discente feminino no curso de Psicologia enquanto que o curso de Economia é marcadamente masculino. Quanto à raça, há maior presença de estudantes pretos e pardos nos cursos de Administração e Direito, que também são os cursos com maior proporção de estudantes não solteiros. Já com relação a condições socioeconômicas, nota-se um perfil de estudantes de renda mais elevada, tendo cursado o ensino médio em rede privada e cujo ingresso não se deu via ação afirmativa nos cursos de Direito e Economia. Por fim, os corpos discentes dos cursos de Administração e Economia são os que estão, em maior proporção, já inseridos no mercado, trabalhando mais de 20 horas semanais (TAB.1 APÊNDICE A).

No que ser refere às instituições de ensino superior, nosso conjunto de dados, apresentados na TAB. 2, APÊNDICE B, contempla estudantes principalmente advindos das regiões Sul e Sudeste do país, que estão vinculados a cursos noturnos em instituições privadas. Estas são, em sua maioria, classificadas como Centros Universitários ou Faculdades. Analisando os cursos individualmente, notase uma distribuição semelhante entre as regiões do país. Já quanto ao turno de oferecimento, destacamse Administração e Direito como cursos predominantemente noturnos, $86 \%$ e 67,1\% dos alunos estão matriculados nesse turno, respectivamente, e já entre os cursos de Economia e Psicologia há maior percentual de alunos em cursos no turno vespertino (cerca de 15\%), se comparado aos demais com cerca de 5\%. Por fim, no que se refere à categoria administrativa e à organização acadêmica em que estão inseridos os cursos, há presença marcada dos cursos de Economia em universidades públicas $(53,4 \%)$, enquanto que os demais cursos estão presentes, predominantemente, em instituições privadas (89,7\% alunos da Administração, 88,6\% do Direito e 84,4\% da Psicologia). 
Partindo para a análise da percepção de dificuldade da prova do ENADE, de modo geral (TAB. 3, APÊNDICE C), observa-se que a categoria de nível de dificuldade médio fica em torno de $60 \%$, enquanto que as diferenças entre as categorias podem ser percebidas marginalmente nos valores das categorias fácil e difícil. A maior diferença nas porcentagens dentro do nível médio de dificuldade está na distinção de sexo: 63,60\% das mulheres consideram a prova de conteúdo geral como nível médio de dificuldade, em comparação a 57,6\% dos homens. Homens e mulheres consideraram a prova fácil na mesma proporção (com cerca de apenas 1\% de diferença), porém, mais homens consideram a prova com nível difícil do que mulheres. Dessa forma, diferente do que se esperaria das mulheres apresentarem menor perspectiva de sucesso na prova, elas a consideram mais fácil, o que não significa que também têm melhor desempenho. (DAL'IGNA, 2007; SILVA; HASENBALG, 2000). De todo modo, há uma diferença importante na percepção de dificuldade entre os dois grupos. Além disso, esse resultado pode ser lido à luz de Bratfish (et al, 1972) que encontraram um aumento relativo da dificuldade percebida entre indivíduos com uma pontuação de alto desempenho no teste do que para indivíduos com uma baixa pontuação de desempenho, ou seja, grupos com melhor desempenho tendem a avaliar a prova como mais difícil, o que pode auxiliar a compreensão das diferenças de gênero.

Já com relação à raça, observam-se diferenças discretas entre as categorias de percepção sobre a prova. Dentre os estudantes que consideram a prova difícil, a maioria é de pretos com diferença de quase três pontos percentuais em relação aos brancos, e são seguidos pelos pardos. Essa tendência é similar para as demais categorias de dificuldade da prova, mas com margens menores. Diferente do resultado para sexo, o grupo racial minoritário é aquele que considera a prova mais difícil. Já quando se analisa o estado civil, nota-se que os estudantes solteiros são os que mais acham a prova difícil (32,8\%) e menos consideram a prova fácil $(8,3 \%)$, comparados com os alunos não solteiros $(14,2 \%$ consideram fácil e $23,7 \%$, difícil).

No que se refere ao trabalho e à renda, os estudantes que trabalham mais de 20 horas semanais e cuja renda domiciliar é de até 1,5 salários mínimo são os que consideram a prova mais difícil. Os resultados são semelhantes quanto ao recebimento de bolsas e ao fato de ter cursado ensino médio em instituição pública: estudantes que não recebem bolsa e advêm de ensino médio em escolas privadas consideram a prova mais fácil. Isso mostra numa relação inversamente proporcional entre condições socioeconômicas e percepção do nível de dificuldade da prova. Entretanto, os estudantes que ingressaram por meio de alguma ação afirmativa ou que recebem algum auxílio financeiro tendem a achar a prova menos difícil. De modo geral, nota-se que os estudantes que consideram a prova mais difícil são, em média, mais velhos do que aqueles que consideram a prova com nível de dificuldade médio e fácil. 
Quanto às características das IES e sua relação com a percepção de dificuldade da prova (TAB. 4, APÊNDICE D e 5, APÊNDICE E), aquelas presentes nas regiões Sul e Sudeste do país são as que possuem mais estudantes que consideram a prova difícil. Nota-se também uma relação bastante clara entre o turno do curso e a percepção de dificuldade da prova: estudantes cujos cursos são matutinos e vespertinos consideram a prova mais fácil, enquanto que aqueles cujos cursos são noturnos consideram-na mais difícil. Isso provavelmente se deve ao nível de dedicação aos estudos, uma vez que, como observado, a maior parte dos estudantes está alocada em cursos noturnos e trabalha mais de 20 horas por semana. Analisando os resultados por curso, observa-se que 27,6\% dos alunos do Direito, 26,3\% dos alunos da Psicologia e 25,9\% dos alunos da Administração consideram a prova difícil, enquanto 24,6\% dos alunos de Economia afirmam ter se deparado com uma prova fácil. Com relação à composição do corpo docente, nota-se que a maior proporção de professores doutores aparece entre as instituições cujos estudantes consideram a prova mais fácil.

Após essa exploração inicial dos dados, tem-se a segunda parte de análise com os modelos explicativos que têm a percepção de dificuldade como variável resposta. Isso resulta em um modelo de regressão logística em dois níveis. Na TAB. 6, APÊNDICE F, apresentada no apêndice, encontram-se os resultados dos modelos executados por curso, que usam as variáveis de características dos estudantes e das instituições para explicar a variação da percepção dos estudantes com relação à dificuldade da prova do ENADE na parte de conteúdo geral.

De maneira geral, os homens tendem a considerar a prova mais difícil que as mulheres, 51,29\% a mais de chances no curso de Administração, 27,89\% entre os alunos do curso de Direito e 27,38\% entre os alunos do curso de Economia ${ }^{14}$ (TAB. 6, APÊNDICE F). Esse resultado é diferente de alguns estudos (DAL'IGNA, 2007; SILVA; HASENBALG, 2000) que ressaltam maior insegurança entre as mulheres e, por consequência, esperar-se-ia uma maior percepção de dificuldade entre elas. Esse resultado, porém, não se verifica para o curso de Psicologia, em que nem raça, nem sexo têm associação com a percepção de dificuldade da prova. Por raça, por sua vez, apenas o curso de Direito aponta que alunos brancos percebem menos dificuldade que seus pares negros $(3,99 \%$ a menos de chance).

No GRAF. 1 abaixo, observam-se os resultados dos modelos com relação à interação entre sexo e raça dos alunos. Em valores preditos, ou seja, a probabilidade estimada através do modelo, aponta-se que no curso de Administração, a probabilidade de um homem negro perceber a prova como

\footnotetext{
${ }^{14} \mathrm{O}$ coeficiente apresentado na tabela foi transformado em percentual no texto, pela seguinte fórmula: $[\exp (\beta)-1] * 100$
} 
difícil é de 29,3\%, enquanto para uma mulher branca essa probabilidade é de $21,7 \%$. No curso de Economia, os homens negros também são os mais prováveis de perceberem a prova como difícil. Já no curso de Psicologia, a probabilidade de um aluno achar a prova difícil é de $24,6 \%$, não tendo diferenças significativas por raça e sexo. 
GRÁfICO 1 - Probabilidade Predita de Percepção Difícil da Prova de Conteúdo Geral do ENADE por Raça e Sexo dos Alunos, Brasil 2015.
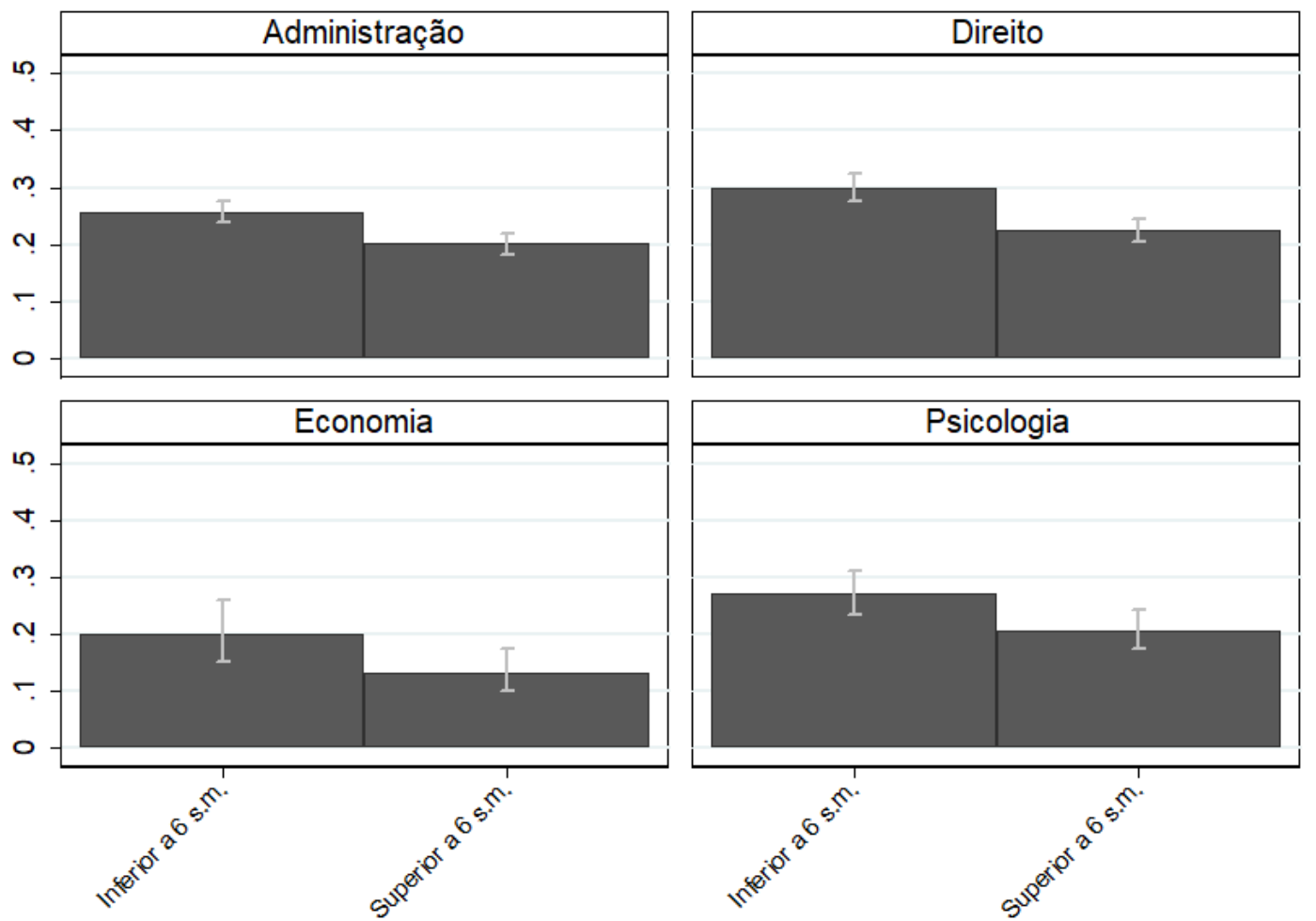

Fonte: Instituto Nacional de Estudos e Pesquisas Anísio Teixeira, 2015.

A percepção de dificuldade da prova tem associação com as variáveis relacionadas à situação socioeconômica dos alunos: renda domiciliar, trabalho, recebimento de bolsa de estudos, ter cursado ensino médio em escola pública e ter entrado via ação afirmativa. Os resultados do GRAF. 2 demonstram que os alunos com maiores níveis de renda são aqueles que consideram a prova mais fácil. Com relação aos alunos que cursaram o ensino médio em escola pública, esses são mais prováveis de perceberem o exame como difícil em relação àqueles que cursaram o ensino médio em escolas particulares.

A análise por renda demonstra que a renda superior a seis salários mínimos tende a indicar menos percepção de dificuldade. No curso de Administração, alunos mais abastados têm probabilidade de $20,0 \%$ de acharem a prova difícil, contra 25,7\% daqueles com renda familiar inferior a seis salários mínimos. No curso de Direito, os valores são de 29,9\% entre os mais pobres, e 22,4\% entre aqueles com maior renda. Tal associação é consistente em todos os quatro cursos analisados. 
GRÁfICO 2 - Probabilidade Predita de Percepção Difícil da Prova de Conteúdo Geral do ENADE por Renda Familiar dos Alunos, Brasil 2015.

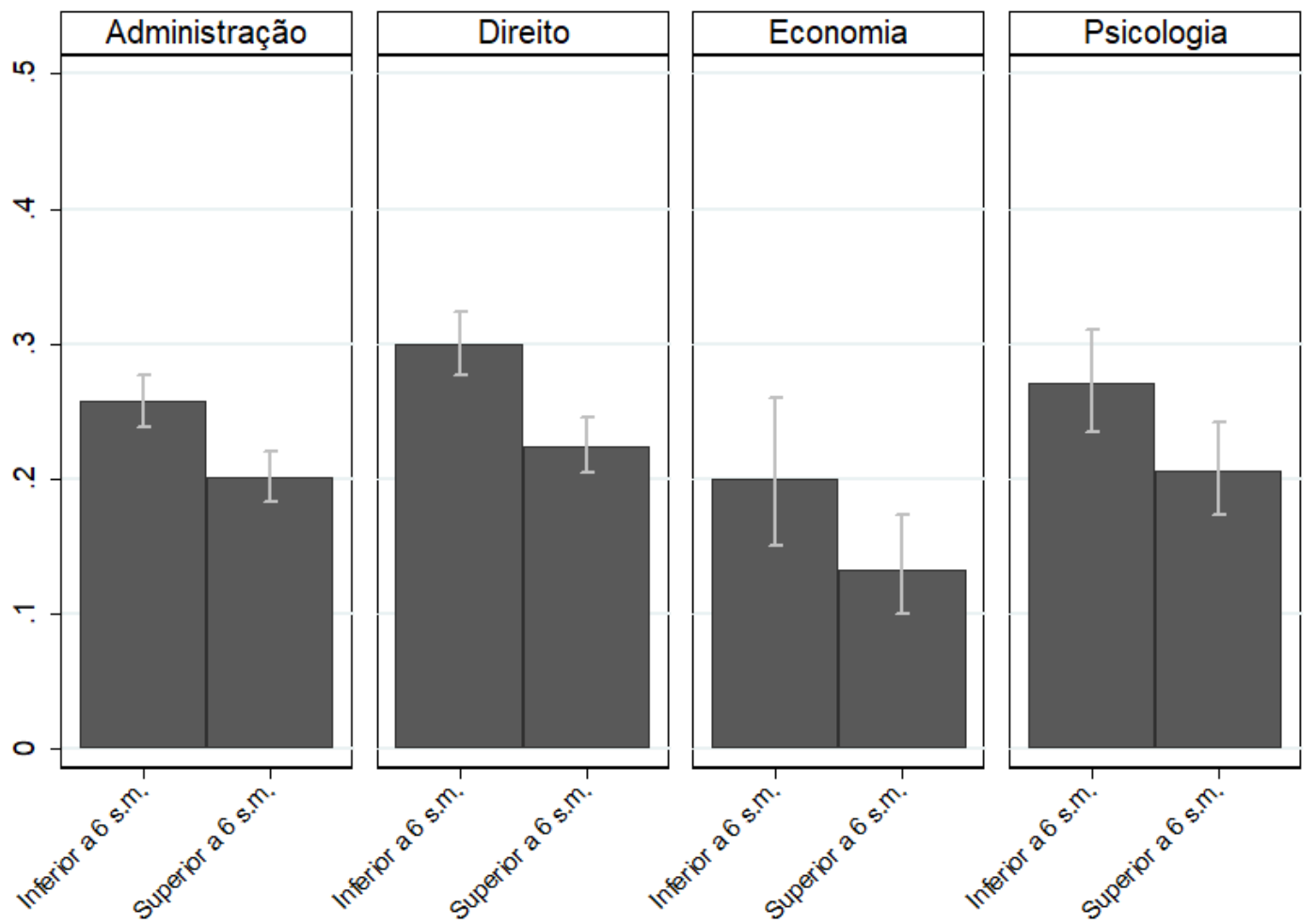

Fonte: Instituto Nacional de Estudos e Pesquisas Anísio Teixeira, 2015.

Por fim, a única variável que caracteriza a IES que se mostrou significativa para os quatro cursos foi percentual de professores com doutorado, que apresentou associação negativa com a probabilidade de percepção de dificuldade sobre a prova. Isto é, em todos os cursos, ter mais professores com esse nível de formação diminui a probabilidade de alunos acharem a prova difícil. No GRAF. 3, observam-se as probabilidades preditas para cada modelo (curso), sendo possível perceber a relação inversamente proporcional: quanto maior proporção de doutores nos cursos de graduação analisados, menores são as chances de os estudantes perceberem a prova do ENADE como difícil. Esse resultado é mais forte para o curso de Direito, cuja reta apresenta maior inclinação. Simm (2015) encontra que a variável mais importante para o resultado do ENADE para o curso de Administração é o percentual de professores com pós-graduação stricto sensu, considerando uma série de variáveis das IES.

Como exemplo, pode-se demonstrar que no curso de Direito, a probabilidade percepção "difícil" por alunos de cursos com menos de $20 \%$ dos docentes com doutorado é de 33,3\%, contra 9,3\% entre cursos com 80\% ou mais de doutores. Já entre os egressos em Psicologia, esses valores são 
de $31,6 \%$ e 10,3\%, respectivamente. Ou seja, a associação entre maior proporção de doutores no corpo docente e percepção de dificuldade da prova é negativa, sendo que ter mais professores com doutorado diminui a probabilidade de achar a prova do ENADE difícil.

GRÁfICO 3 - Probabilidade Predita de Percepção Difícil da Prova de Conteúdo Geral do ENADE por Percentual de Professores com Doutorado, Brasil 2015.

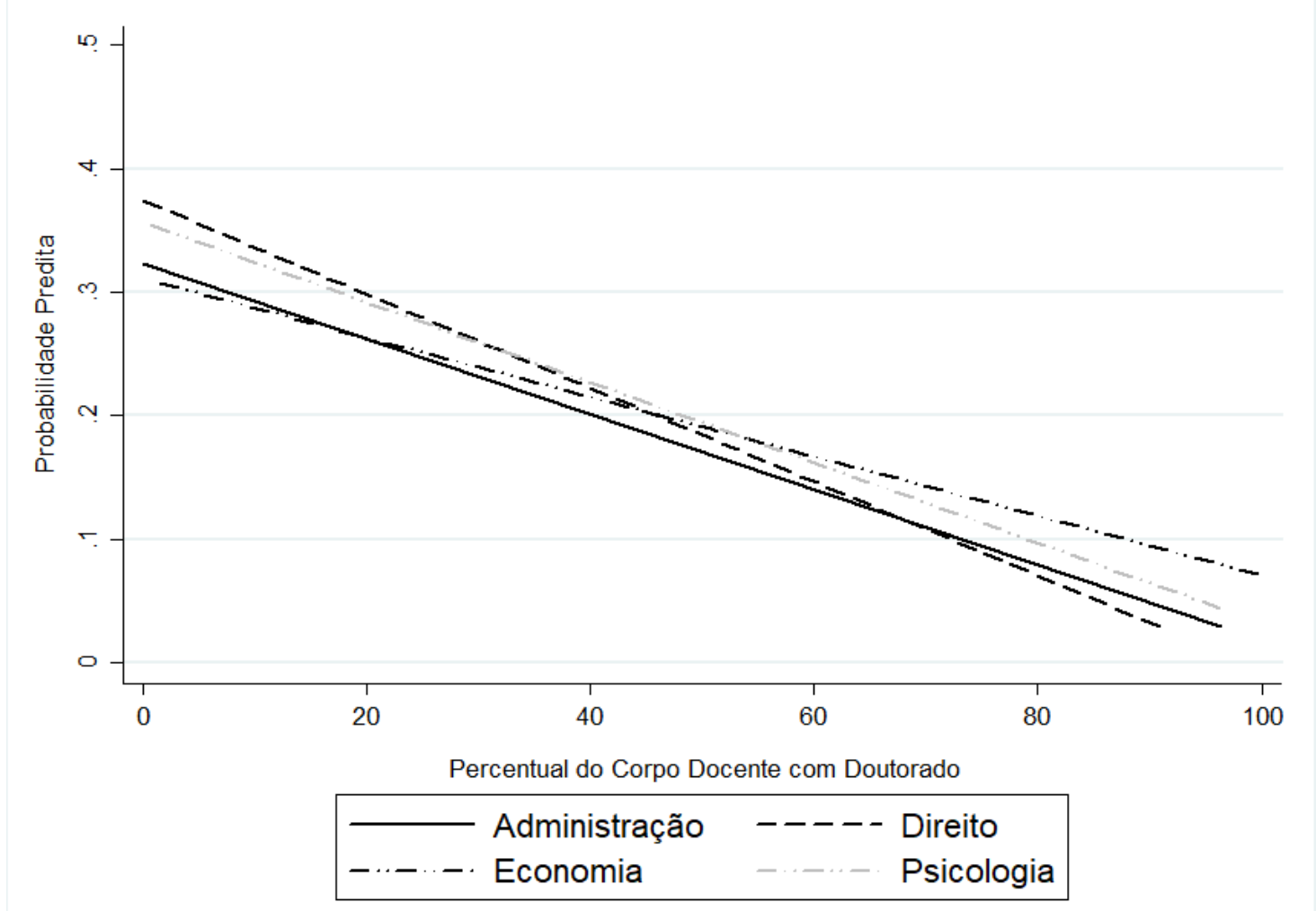

Fonte: Instituto Nacional de Estudos e Pesquisas Anísio Teixeira, 2015.

Outras características das IES são significativas apenas para alguns cursos. Para os cursos de Administração e Direito, estar vinculado a instituições da região Nordeste diminui a chance de os alunos considerarem a prova difícil, tomando a região Norte como categoria de referência. Para esses mesmos cursos, a chance de considerar a prova difícil aumenta para estudantes do Sudeste, Sul e Centro-Oeste do país. No que se refere ao turno, ser de cursos de Direito noturnos aumenta a chance de considerar a prova difícil. Por fim, um resultado interessante para o caso da Psicologia: o aluno estar vinculado a IES privada ou pública municipal aumenta a chance de achar a prova difícil.

A partir dos resultados apresentados, destaca-se que as características de origem social dos alunos são importantes para o entendimento da percepção de dificuldade do ENADE, já que mesmo controlando por características da IES, observa-se que as características socioeconômicas têm um papel relevante para se analisar a percepção de dificuldade do Exame. É importante destacar que indicam 
diferenças que se iniciam antes do ingresso no ensino superior e seguem até seu término no momento de realização da prova, incluindo também treino prévio para prova, acesso a outros tipos de materiais para além da universidade, diferenças na formação básica. Esse resultado difere de outras análises que buscam explicar o rendimento como, por exemplo, Crepalde e Silveira (2016) que apontam a nota da prova como um fator mediador das características da IES, argumentando que a diferenciação por instituição de ensino tem um efeito atenuador na dimensão das desigualdades de gênero, raça e renda familiar. Essa diferença nos resultados pode apontar que a percepção de dificuldade de uma prova relaciona-se mais com os indivíduos e suas trajetórias escolares do que a análise de sua nota, que seria o resultado da interação entre caraterísticas individuais e institucionais. Tanto que a única variável da instituição que foi significativa para todos os cursos analisados é o percentual de doutores que pode tanto se relacionar com a qualidade das aulas, mas também com aspectos relacionados ao nível de confiança dos alunos.

\section{CONCLUSÃO}

O artigo teve como foco analisar a percepção de dificuldade da prova do ENADE à luz de características individuais e socioeconômicas dos estudantes, e de características das instituições de ensino superior. Para isso, foram selecionados os cursos de Administração, Direito, Economia e Psicologia, em que seus alunos, com mais de 80\% do curso concluído, prestaram o Exame Nacional de Desempenho (ENADE) em 2015. A análise foi realizada através do modelo logístico de dois níveis, já que se sabe da importância de se considerar em um mesmo modelo a dimensão individual e a dimensão da instituição de ensino.

Os resultados da percepção de dificuldade apontam que as características individuais e aquelas relacionadas às condições socioeconômicas são importantes para sua compreensão e que apenas o percentual de doutores é significativo dentre as variáveis das IES analisadas. A partir destes resultados, é possível concluir que, no que se refere à percepção da dificuldade da prova, as características da origem social dos estudantes têm um papel relevante. Isso porque elas refletem as condições anteriores à realização da prova que influenciam a percepção, como a possibilidade de acesso a outras fontes de conhecimento para além daquelas fornecidas pelos cursos de ensino superior. Nesse sentido, apesar do efeito escola atenuar os efeitos das características individuais no desempenho na prova, conforme encontrado na literatura, as características socioeconômicas têm um papel relevante para se analisar a percepção de dificuldade. 
No que se refere ao papel das instituições de ensino na determinação da percepção de dificuldade dos estudantes, destaca-se a relevância do nível de formação do corpo docente. Seja por trazer maior bagagem de conhecimento formal e proporcionar maior qualidade para o processo de ensino, por proporcionar maior confiança aos alunos ou por algum outro fator, a composição do corpo docente importa.

Estudos sobre a percepção de dificuldade da prova independente do desempenho dos alunos são importantes porque apresentam outra face da desigualdade educacional e demonstram ser um fenômeno independente do resultado alcançado pelo aluno, ou seja, embora as variáveis que as explicam sejam semelhantes, a construção do processo de percepção é diferente, sendo muitas vezes, uma relação inversa.

\section{REFERÊNCIAS}

AMARAL E.; NEVES, A.; SILVA, A.; MONTEIRO, T.. Análise do perfil dos alunos ingressantes na UFMG pela iniciativa do bônus sociorracial. Teoria \& Sociedade, vol. 20(1), p. 85-116, 2012.

BORG, G. Interindividual scaling and perception of muscular force. Kungl. Fysiogr. Sällsk., Lund Förh., 12, p. 117-125, 1961.

.; FORSLING, S. A psychophysical study on perceived difficulty. Educational and Psychological Research Bulletin. Umeå University. N. 1, 1964.

. Nagra psykofysiska tillampningar. Nordisk Psykologi, 1966, 18, p. 300-315 (in Swedish) apud BRATFISH, O.; DORNIČ, S.; BORG, G. Perceived Difficulty of Items in A Test of Reasoning Ability. Reports from the Institute of Applied Psychology, Univesity of Stockholm, n.28, 1972.

.; BRATFISH, O.; DORNIČ, S. On perceived difficult. Reports from the Institute of Applied Psychology, Univesity of Stockolm, n.1, 1970

.; _ . On the problems of perceived difficult. Scandinavian Journal of Psychology, V. 12, n.1, 1971.

BOURDIEU, P. Distinção: Crítica Social do Julgamento. Porto Alegre: Zouk; São Paulo: EDUSP, $2^{\mathrm{a}}$ ed, 2011.

BRASIL. Lei No 10.861, de 14 de Abril de 2004. Institui o Sistema Nacional de Avaliação da Educação Superior - SINAES e dá outras providências. Diário Oficial da União, Poder Executivo, Brasília, DF, 15 abr. 2004. Disponível em: <http://www.planalto.gov.br/ccivil_03/_Ato20042006/2004/Lei/L10.861.htm>. Acesso em: 22 jul. 2020. 
Lei $\mathrm{n}^{\circ} 12.711$ de 29 de agosto de 2012. Dispõe sobre o ingresso nas universidades federais e nas instituições federais de ensino técnico de nível médio e dá outras providências. Diário Oficial da União, Poder Legislativo, Brasília, DF, 29 ago. 2012. Disponível em: <http://www.planalto.gov.br/ccivil_03/_ato2011-2014/2012/lei/112711.htm>. Acesso em: 22 jul. 2020.

BRATFISH, O.; DORNIČ, S.; BORG, G. Perceived Difficulty of Items in A Test of Reasoning Ability. Reports from the Institute of Applied Psychology, Univesity of Stockholm, n.28, 1972.

BRITO, T. Corpo Docente: Fatores determinantes do desempenho discente no ENADE. 2015. $90 \mathrm{f}$. Dissertação (Mestrado em Administração) - Faculdade de Economia, Administração e Contabilidade, Universidade de São Paulo, São Paulo, 2015.

CARMO, C.; ALMEIDA, S. Exame Nacional de Avaliação de Desempenho dos Estudantes (ENADE): a influência de variáveis qualitativas no desempenho dos alunos dos cursos de ciências contábeis no Brasil. Revista de Auditoria, Governança e Contabilidade, v.3, n.7, p.71-87, 2015.

CARVALHAES, F.; RIBEIRO, C. Estratificação horizontal da educação superior no Brasil: Desigualdades de classe, gênero e raça em um contexto de expansão educacional. Tempo Social, revista de sociologia da USP, v. 31, n. 1, p. 195-233, 2019.

CARVALHO, M.; WALTEMBERG, F. Desigualdade de oportunidades no acesso ao Ensino Superior no Brasil: uma comparação entre 2003 e 2013. Economia Aplicada, v. 19, n. 2, p. 369-396, 2015.

CREPALDE, N.; SILVEIRA, L. Desempenho universitário no Brasil: estudo sobre desigualdade educacional com dados do Enade 2014. Revista Brasileira de Sociologia, Vol. 04, No. 07, p. 211-238, Jan. Jun., 2016.

DELIGNIÈRES, D. Perceived Difficulty, Resources Investment and Motor Performance. Psychology for Physical Educators, 1999.

DUBET, F. Qual democratização do ensino superior?. Cadernos CRH, v. 28, n. 74, p. 255-265, 2015.

DAL'IGNA, M. C. Desempenho escolar de meninos e meninas: há diferença? Educação em Revista, Belo Horizonte. N 46. p. 241 - 261. 2007.

FERNANDES, D. Estratificação Educacional, Origem Socioeconômica e Raça no Brasil: As Barreiras da Cor. Premio IPEA 40 Anos. Brasília: IPEA, 2005.

GISI, M. A Educação Superior no Brasil e o caráter de desigualdade do acesso e da permanência. Revista Diálogo Educacional, Curitiba, v. 6, n.17, p. 97-112, jan./abr, 2006.

HONG, E. The anxiety, perceived test difficult, and test performance: temporal patterns of their effect. Learning and Individual Differences, v.11, n.4, p. 431-447, 1999. 
INSTITUTO NACIONAL DE ESTUDOS E PESQUISAS ANÍSIO TEIXEIRA. Sinopse Estatística do Ensino Superior. Brasília: INEP, 1995.

Sinopse Estatística do Ensino Superior. Brasília: INEP, 2015.

JARUSCH, H. Higher Education and Social Change: some comparative perspectives. In:

(Org.) The transformation of Higher Education 1860-1930. Chicago: University of Chicago Press, 1983.

JEZINE, E. Expansão e Acesso à Educação Superior: Como fica a igualdade de gênero? Revista Internacional de Educação Superior. Campinas, SP v.2 n.3 p.430-449 set./dez. 2016.

KING, G.; KEOHANE, R. O.; VERBA, S. Designing Social Inquiry: Scientific Inference in Qualitative Research. Princeton, New Jersey: Princeton University Press, 1994.

LEMOS, K.; MIRANDA, G. Alto e Baixo Desempenho no Enade: que variáveis explicam? Revista Ambiente Contábil, UFRN, Vol. 7. n. 2, p. 101-118, jul./dez. 2015.

MARTELETO, L.; MARSCHNER, M.; CARVALHAES, F. Educational Stratification after a decade of reforms on higher education access in Brazil. Research in Social Stratification and Mobility, v.46, p. 99-111, 2016.

MARTINS, C. Reconfiguring higher education in Brazil: the participation of private institutions. Análise Social, n. 208, v. XLVIII (3º, p. 621-658, 2013.

MENDES, I.; COSTA, B. Considerações sobre o Papel do Capital Cultural e Acesso ao Ensino Superior: Uma Investigação com Dados de Minas Gerais. Educação em Revista, v. 31, n. 03, p. 71 95, 2015.

OLIVEIRA, A.; SILVA, I. Políticas de Inclusão no Ensino Superior Brasileiro: Um Estudo sobre o Perfil Socioeconômico de Estudantes nos Anos 2010 a 2012. Educação em Revista, n. 33, p. 1-28, 2017.

PICANÇO, F. Juventude por Cor e Renda no Acesso ao Ensino Superior: Somando desvantagens, multiplicando desigualdade? RBCS, Vol. 30 n. 88, p. 145-181, junho, 2015.

RAFTERY, A.; HOUT, M. Maximally Maintained Inequality: Expansion, Reform, and Opportunity in Irish Education, 1921-75. Sociology of Education, vol. 66, no. 1, p. 41-62, 1993.

RIBEIRO, C. Classe, raça e mobilidade social no Brasil. DADOS - Revista de Ciências Sociais, vol. 49, n. 4, p. 833-873, 2006.

Desigualdade de Oportunidades e Resultados Educacionais no Brasil. DADOS - Revista de Ciências Sociais, Rio de Janeiro, vol. 54, no 1, p. 41-87, 2011. 
Desigualdades de gênero no ensino superior e no mercado de trabalho no Brasil: uma análise de idade, período e coorte. Revista Sociedade e Estado - Vol. 31, n. 2, maio/ago., p. 301-323, 2016.

RICOLDI, A.; ARTES, A. Mulheres no Ensino Superior Brasileiro: Espaço Garantido e Novos Desafios. Ex Aequo, n. 33, pp. 149-161, 2016.

RODRIGUES, D.; SANTOS, N.; SANTANA, M.; LEMES, A. Diferenças entre gênero, etnia e perfil socioeconômico no exame nacional de desempenho do estudante do curso de ciências contábeis. Revista Contemporânea de Contabilidade - UFSC, Florianópolis, v. 14, n. 33, p. 101-117, set./dez., 2017.

ROWE, D.; BASTOS, A. Vínculos com a Carreira e Produção Acadêmica: Comparando Docentes de IES Públicas e Privadas. Revista de Administração Contemporânea, Curitiba, v. 14, n. 6, art. 2, p. 1011-1030, Nov./Dez., 2010.

SANTOS, Y. G. As Mulheres como Pilar da Construção dos Programas Sociais. Cadernos CRH, vol. 27, n. 72, 2014, p. 479-494, 2014.

SEWELL, W.; SHAH, V. Socioeconomic Status, Intelligence, and the Attainment of Higher Education. Sociology of Education, Vol. 40, No. 1, p. 1-23, 1967.

SILVA, N.; HASENBALG, C. Tendências da Desigualdade Educacional no Brasil. DADOS - Revista de Ciências Sociais, vol. 43, n. 3, p. 423-445, 2000.

SIMM, E. B. A qualidade dos cursos de administração no Brasil e no Paraná mensurada através dos indicadores do ENADE. Cadernos da Escola de Negócios, vol.1, n. 13, p 16-29. 2015.

TACHIBANA, T.; MENEZES FILHO, N.; KOMATSU, B. Ensino Superior no Brasil. INSPER Policy Paper, n. 14, 2015. Disponível em: <https://www.insper.edu.br/wpcontent/uploads/2018/09/Ensino-superior-no-Brasil.pdf>. Acesso em: 22 jul. 2020.

TELLES, R.; MARINHO, S. Análise da relação do desempenho discente em comparação com as características dos docentes e das Instituições de Ensino Superior. Revista Inova Ação, Teresina, v. 3, n. 1, art. 5, p. 71-87, jan./jun. 2014.

UNESCO. Acesso, permanência, aprendizagem e conclusão da educação básica na idade certa (Resumo Executivo). Brasília: UNICEF, 2012.

VERHINE, R. E.; DANTAS, L. M. V.; SOARES, J. F. Do provão ao Enade: uma análise comparativa dos exames nacionais utilizados no ensino superior brasileiro. Revista Ensaio: avaliação de políticas públicas educacionais. Rio de Janeiro. N. 52, V. 12, p. 291- 310., 2006.

WEBER, C. Jr; BIZER, G. Y. The Effects of Immediate Forewarning of Test Difficulty on Test Performance. The Journal of General Psychology, v. 133, n. 3, p. 277-285, 2006. 


\section{APÊNDICE A}

TABELA 1

Características dos Estudantes por Curso (\%)

Administração Direito Economia Psicologia Total)

\begin{tabular}{|c|c|c|c|c|c|c|}
\hline \multirow{2}{*}{ Sexo } & Feminino & 58,1 & 54,7 & 41,8 & 83,2 & 58,6 \\
\hline & Masculino & 41,9 & 45,3 & 58,2 & 16,8 & 41,4 \\
\hline \multirow{3}{*}{ Cor/raça } & Branca & 61,2 & 63,0 & 68,3 & 63,3 & 62,3 \\
\hline & Preta & 7,4 & 7,2 & 6,4 & 7,7 & 7,3 \\
\hline & Parda & 31,4 & 29,7 & 25,3 & 29,0 & 30,3 \\
\hline \multirow{2}{*}{ Estado civil } & Solteiro & 68,4 & 71,8 & 84,1 & 72,1 & 70,6 \\
\hline & Não Solteiro & 31,6 & 28,2 & 15,9 & 27,9 & 29,4 \\
\hline \multirow{7}{*}{ Renda } & Ate 1,5 salário & 10,4 & 9,0 & 6,7 & 11,5 & 9,9 \\
\hline & De 1,5 até 3 salários & 26,8 & 19,6 & 15,9 & 25,2 & 23,4 \\
\hline & De 3 até 4,5 salários & 22,7 & 17,2 & 16,5 & 20,3 & 20,1 \\
\hline & De 4,5 até 6 salários & 14,5 & 14,2 & 12,8 & 13,6 & 14,3 \\
\hline & De 6 até 10 salários & 14,3 & 18,5 & 18,9 & 16,2 & 16,3 \\
\hline & De 10 até 30 salários & 8,8 & 17,0 & 21,1 & 11,1 & 12,7 \\
\hline & Acima de 30 salários & 2,5 & 4,4 & 8,1 & 2,2 & 3,4 \\
\hline \multirow{3}{*}{ Trabalho } & Não trabalha & 23,9 & 48,2 & 37,3 & 61,4 & 37,6 \\
\hline & Até $20 \mathrm{~h}$ semanais & 4,5 & 8,2 & 4,8 & 7,2 & 6,2 \\
\hline & Acima de $20 \mathrm{~h}$ semanais & 71,7 & 43,6 & 57,9 & 31,5 & 56,2 \\
\hline \multirow{3}{*}{ Bolsa } & Curso gratuito & 10,1 & 9,1 & 58,1 & 13,5 & 11,5 \\
\hline & Curso pago & 46,4 & 45,8 & 23,5 & 35,6 & 44,4 \\
\hline & Recebe alguma bolsa & 43,4 & 45,2 & 18,4 & 51,0 & 44,1 \\
\hline \multirow{2}{*}{ Auxílio } & Recebe algum auxílio & 3,6 & 3,6 & 11,0 & 7,0 & 4,1 \\
\hline & Não recebe & 96,4 & 96,4 & 89,0 & 93,0 & 95,9 \\
\hline Ação & Ingresso com ação afirmativa & 20,3 & 14,2 & 17,3 & 16,8 & 17,5 \\
\hline Afirmativa & Ingresso sem ação afirmativa & 79,7 & 85,8 & 82,7 & 83,2 & 82,5 \\
\hline Ensino & Em instituição privada & 24,6 & 44,8 & 50,0 & 37,7 & 34,7 \\
\hline \multirow[t]{2}{*}{ Médio } & Em instituição pública & 75,4 & 55,2 & 50,0 & 62,3 & 65,3 \\
\hline & To & 14893 & 96771 & 7357 & 22583 & 41604 \\
\hline
\end{tabular}

Fonte: Instituto Nacional de Estudos e Pesquisas Anísio Teixeira, 2015. 
APÊNDICE B

TABELA 2

Características das IES por Curso (\%)

\begin{tabular}{rrrrr} 
Administração & Direito & Economia & Psicologia & Total \\
\hline 3,6 & 6,5 & 6,2 & 5,0 & 5,0
\end{tabular}

\begin{tabular}{clrrrrr}
\hline \multirow{5}{*}{ Região } & Norte & 3,6 & 6,5 & 6,2 & 5,0 & 5,0 \\
& Nordeste & 14,3 & 21,7 & 17,6 & 22,0 & 18,0 \\
& Sudeste & 46,0 & 40,2 & 48,2 & 45,4 & 43,7 \\
& Sul & 27,1 & 19,2 & 21,4 & 19,2 & 23,0 \\
& Centro-Oeste & 9,0 & 12,4 & 6,6 & 8,3 & 10,2 \\
\hline \multirow{3}{*}{ Turno } & Curso matutino & 10,7 & 27,5 & 20,4 & 23,9 & 18,9 \\
& Curso vespertino & 3,3 & 5,5 & 14,6 & 14,4 & 5,6 \\
& Curso noturno & 86,0 & 67,1 & 65,0 & 61,7 & 75,5 \\
\hline \multirow{3}{*}{ Categoria } & Público Federal & 6,2 & 6,0 & 44,6 & 11,4 & 7,8 \\
Administrativa & Público Estadual & 2,2 & 2,0 & 7,1 & 1,6 & 2,2 \\
& Público Municipal & 1,8 & 3,4 & 1,7 & 2,6 & 2,5 \\
& Privada & 89,7 & 88,6 & 46,6 & 84,4 & 87,5 \\
\hline \multirow{2}{*}{ Organização } & IF e CEFET & 0,5 & 0,0 & 0,0 & 0,0 & 0,3 \\
Acadêmica & Centro Univ./ Faculdade & 55,4 & 56,8 & 16,7 & 48,1 & 54,1 \\
& Universidade & 44,1 & 43,2 & 83,3 & 51,9 & 45,6 \\
& & 114893 & $\mathbf{9 6 7 7 1}$ & $\mathbf{7 3 5 7}$ & $\mathbf{2 2 5 8 3}$ & $\mathbf{2 4 1 6 0 4}$ \\
\hline
\end{tabular}

Fonte: Instituto Nacional de Estudos e Pesquisas Anísio Teixeira, 2015. 


\section{APÊNDICE C}

TABELA 3

Características dos Estudantes pela Percepção de Dificuldade

Fácil Médio Difícil

\begin{tabular}{|c|c|c|c|c|c|}
\hline & & $\begin{array}{c}\text { Fácil } \\
(\%)\end{array}$ & $\begin{array}{c}\text { Médio } \\
(\%)\end{array}$ & $\begin{array}{c}\text { Difícil } \\
(\%)\end{array}$ & Qui-Quadrado \\
\hline \multirow{2}{*}{ Sexo } & Feminino & 12,0 & 63,6 & 24,4 & 924,43 \\
\hline & Masculino & 13,2 & 57,6 & 29,2 & df:2 $(0,000)$ \\
\hline \multirow{3}{*}{ Cor/raça } & Branca & 13,4 & 60,8 & 25,8 & \multirow{3}{*}{$\begin{array}{r}360,054 \\
d f: 4(0,000)\end{array}$} \\
\hline & Preta & 11,6 & 59,7 & 28,7 & \\
\hline & Parda & 10,8 & 62,0 & 27,1 & \\
\hline \multirow{2}{*}{ Estado civil } & Solteiro & 8,3 & 58,9 & 32,8 & \multirow{2}{*}{$\begin{array}{r}3041,636 \\
d f: 2(0,000) \\
\end{array}$} \\
\hline & Não Solteiro & 14,2 & 62,0 & 23,7 & \\
\hline \multirow{7}{*}{ Renda } & Até 1,5 salário & 10,0 & 59,6 & 30,4 & \multirow{7}{*}{$\begin{array}{r}4991,469 \\
\text { df:12 }(0,000)\end{array}$} \\
\hline & De 1,5 até 3 salários & 9,5 & 61,1 & 29,4 & \\
\hline & De 3 até 4,5 salários & 10,2 & 61,9 & 28,0 & \\
\hline & De 4,5 até 6 salários & 11,5 & 61,5 & 27,0 & \\
\hline & De 6 até 10 salários & 13,5 & 61,4 & 25,1 & \\
\hline & De 10 até 30 salários & 19,2 & 61,4 & 19,4 & \\
\hline & Acima de 30 salários & 28,3 & 57,1 & 14,7 & \\
\hline \multirow{3}{*}{ Trabalho } & Não trabalha & 14,9 & 61,5 & 23,6 & \multirow{3}{*}{$\begin{array}{r}1323,266 \\
\text { df:4 }(0,000)\end{array}$} \\
\hline & Até $20 \mathrm{~h}$ semanais & 13,6 & 61,9 & 24,5 & \\
\hline & Acima de $20 \mathrm{~h}$ semanais & 10,7 & 60,8 & 28,5 & \\
\hline \multirow{3}{*}{ Bolsa } & Curso gratuito & 24,3 & 60,1 & 15,6 & \multirow{3}{*}{$\begin{array}{r}5072,64 \\
\text { df:4 }(0,000)\end{array}$} \\
\hline & Curso pago & 11,7 & 61,4 & 26,9 & \\
\hline & Recebe alguma bolsa & 10,2 & 61,1 & 28,7 & \\
\hline \multirow{2}{*}{ Auxílio } & Não recebe & 12,4 & 61,1 & 26,4 & 36,173 \\
\hline & Recebe algum auxílio & 14,4 & 60,3 & 25,3 & df:2 $(0,000)$ \\
\hline Ação & Ingresso sem ação afirmativa & 12,7 & 60,9 & 26,5 & 44,73 \\
\hline Afirmativa & Ingresso com ação afirmativa & 11,6 & 62,3 & 26,1 & df:2 $(0,000)$ \\
\hline \multirow{2}{*}{ Ensino Médio } & Em instituição privada & 18,4 & 62,8 & 18,8 & 6534,846 \\
\hline & Em instituição pública & 9,3 & 60,2 & 30,5 & df:2 $(0,000)$ \\
\hline
\end{tabular}

Fonte: Instituto Nacional de Estudos e Pesquisas Anísio Teixeira, 2015. 


\section{APÊNDICE D}

TABELA 4

Características das IES pela Percepção de Dificuldade

\begin{tabular}{|c|c|c|c|c|c|}
\hline & & $\begin{array}{c}\text { Fácil } \\
(\%)\end{array}$ & $\begin{array}{c}\text { Médio } \\
(\%)\end{array}$ & $\begin{array}{c}\text { Difícil } \\
(\%)\end{array}$ & Qui-Quadrado \\
\hline \multirow{5}{*}{ Região } & Norte & 11,3 & 62,4 & 26,2 & \multirow{5}{*}{$\begin{array}{r}1419,529 \\
\text { df:8 }(0,000)\end{array}$} \\
\hline & Nordeste & 14,0 & 64,8 & 21,2 & \\
\hline & Sudeste & 13,4 & 60,8 & 25,8 & \\
\hline & Sul & 10,4 & 59,4 & 30,2 & \\
\hline & Centro-Oeste & 11,2 & 59,1 & 29,8 & \\
\hline \multirow{3}{*}{ Turno } & Curso matutino & 27,4 & 59,8 & 12,8 & \multirow{3}{*}{$\begin{array}{r}2916,733 \\
\text { df:4 }(0,000)\end{array}$} \\
\hline & Curso vespertino & 20,3 & 61,0 & 18,8 & \\
\hline & Curso noturno & 11,2 & 59,0 & 29,8 & \\
\hline \multirow{4}{*}{$\begin{array}{l}\text { Categoria } \\
\text { Administrativa }\end{array}$} & Público Federal & 11,0 & 61,3 & 27,7 & \multirow{4}{*}{$\begin{array}{r}5600,545 \\
\text { df:6 (0,000) }\end{array}$} \\
\hline & Público Estadual & 21,0 & 62,4 & 16,7 & \\
\hline & Público Municipal & 10,2 & 61,0 & 28,8 & \\
\hline & Privada & 15,2 & 61,2 & 23,6 & \\
\hline \multirow{3}{*}{$\begin{array}{l}\text { Organização } \\
\text { Acadêmica }\end{array}$} & IF e CEFET & 16,1 & 61,7 & 22,2 & \multirow{3}{*}{$\begin{array}{r}1885,342 \\
\text { df:4 }(0,000)\end{array}$} \\
\hline & Centro Univ./ Faculdade & 22,5 & 60,6 & 16,9 & \\
\hline & Universidade & 10,9 & 61,0 & 28,2 & \\
\hline \multirow{4}{*}{ Curso } & Administração & 10,8 & 63,2 & 25,9 & \multirow{4}{*}{$\begin{array}{r}1664,086 \\
\text { df:6 (0,000) }\end{array}$} \\
\hline & Direito & 13,6 & 58,8 & 27,6 & \\
\hline & Economia & 24,6 & 57,3 & 18,1 & \\
\hline & Psicologia & 11,9 & 61,7 & 26,3 & \\
\hline
\end{tabular}

Fonte: Instituto Nacional de Estudos e Pesquisas Anísio Teixeira, 2015. 


\section{APÊNDICE E}

TABELA 5

Características dos Estudantes e das IES pela Percepção de Dificuldade

\begin{tabular}{clcc} 
& & Média & Desvio-padrão \\
\hline \multirow{4}{*}{ Fácil } & Idade dos Estudantes & 27 & 6,54 \\
& Proporção de Docentes Doutores & 34,7 & 24,3 \\
& Proporção de Docentes Mulheres & 44,6 & 7,78 \\
& Proporção de Docentes Não Brancos & 45,5 & 30,9 \\
\hline \multirow{4}{*}{ Médio } & Idade dos Estudantes & 28.4 & 7,53 \\
& Proporção de Docentes Doutores & 25,1 & 18,6 \\
& Proporção de Docentes Mulheres & 45,5 & 8,06 \\
& Proporção de Docentes Não Brancos & 42,5 & 30,2 \\
\hline \multirow{5}{*}{ Difícil } & Idade dos Estudantes & 30 & 8,31 \\
& Proporção de Docentes Doutores & 40,7 & 14,8 \\
& Proporção de Docentes Mulheres & 45,9 & 8,22 \\
& Proporção de Docentes Não Brancos & 38,8 & 29,2 \\
\hline \multirow{2}{*}{ Total } & Idade dos Estudantes & 28,63 & 7.68 \\
& Proporção de Docentes Doutores & 25,12 & 18,98 \\
& Proporção de Docentes Mulheres & 45,53 & 8,07 \\
& Proporção de Docentes Não Brancos & 41,86 & 30,11 \\
\hline
\end{tabular}

Fonte: Instituto Nacional de Estudos e Pesquisas Anísio Teixeira, 2015. 


\section{APÊNDICE F}

TABELA 6

Coeficientes da Regressão Logística Multinível para Percepção de Dificuldade

\begin{tabular}{|c|c|c|c|c|}
\hline & Administração & Direito & Economia & Psicologia \\
\hline \multirow{2}{*}{ Masculino } & $0.414 * * *$ & $0.246^{* * *}$ & $0.242^{* *}$ & -0.0213 \\
\hline & $(0.0225)$ & $(0.0247)$ & $(0.108)$ & $(0.0671)$ \\
\hline \multirow{2}{*}{ Branca } & 0.00748 & $-0.0408^{*}$ & 0.00174 & -0.00107 \\
\hline & $(0.0200)$ & $(0.0228)$ & $(0.106)$ & $(0.0390)$ \\
\hline \multirow{2}{*}{ Branca - Masculino } & $-0.0618^{* *}$ & $-0.0623^{* *}$ & -0.171 & -0.00524 \\
\hline & $(0.0287)$ & $(0.0310)$ & $(0.133)$ & $(0.0867)$ \\
\hline \multirow{2}{*}{ Solteiro } & $-0.112^{* * *}$ & $-0.144^{* * *}$ & -0.236 *** & $-0.159 * * *$ \\
\hline & $(0.0170)$ & $(0.0198)$ & $(0.0886)$ & $(0.0408)$ \\
\hline \multirow{2}{*}{ Idade } & $0.0133 * * *$ & $0.0167 * * *$ & $0.0250 * * *$ & $0.0148^{* * *}$ \\
\hline & $(0.00117)$ & $(0.00107)$ & $(0.00614)$ & $(0.00219)$ \\
\hline \multirow{2}{*}{ Renda Acima de 6 s.m. } & $-0.145^{* * *}$ & $-0.162 * * *$ & $-0.217 * * *$ & $-0.207 * * *$ \\
\hline & $(0.0187)$ & $(0.0178)$ & $(0.0757)$ & $(0.0407)$ \\
\hline Não trabalha & Ref. & Ref. & Ref. & Ref. \\
\hline \multirow{2}{*}{ Trabalho: Até 20h } & 0.0361 & 0.00507 & $-0.282^{*}$ & $-0.109 *$ \\
\hline & $(0.0373)$ & $(0.0292)$ & $(0.170)$ & $(0.0641)$ \\
\hline \multirow{2}{*}{ Trabalho: Acima 20h } & $0.0756^{* * *}$ & $0.0351 * *$ & $0.142^{*}$ & 0.00513 \\
\hline & $(0.0176)$ & $(0.0172)$ & $(0.0736)$ & $(0.0358)$ \\
\hline Bolsa: curso gratuito & Ref. & Ref. & Ref. & Ref. \\
\hline \multirow[t]{2}{*}{ Bolsa: curso pago } & 0.0270 & 0.0203 & -0.247 & -0.163 \\
\hline & $(0.0661)$ & $(0.0816)$ & $(0.152)$ & $(0.147)$ \\
\hline \multirow[t]{2}{*}{ Bolsa: recebe alguma } & -0.0886 & 0.00992 & $-0.447 * * *$ & -0.127 \\
\hline & $(0.0662)$ & $(0.0816)$ & $(0.146)$ & $(0.146)$ \\
\hline \multirow{2}{*}{ Recebe auxílio } & $0.0697 *$ & -0.0025 & 0.111 & 0.0003 \\
\hline & $(0.0399)$ & $(0.0416)$ & $(0.110)$ & $(0.0705)$ \\
\hline \multirow{2}{*}{ Teve Ação Afirmativa } & $-0.0742 * * *$ & $-0.0999 * * *$ & -0.0674 & $-0.132 * * *$ \\
\hline & $(0.0184)$ & $(0.0230)$ & $(0.0919)$ & $(0.0464)$ \\
\hline \multirow{2}{*}{ EM Público } & $0.322^{* * *}$ & $0.321 * * *$ & $0.251 * * *$ & $0.282 * * *$ \\
\hline & $(0.0202)$ & $(0.0182)$ & $(0.0781)$ & $(0.0394)$ \\
\hline Norte & Ref. & Ref. & Ref. & Ref. \\
\hline \multirow[t]{2}{*}{ Nordeste } & $-0.254 * * *$ & $-0.167 * *$ & 0.0375 & $-0.198^{*}$ \\
\hline & $(0.0683)$ & $(0.0650)$ & $(0.174)$ & $(0.118)$ \\
\hline \multirow[t]{2}{*}{ Sudeste } & $0.181^{* * *}$ & $0.257 * * *$ & -0.0332 & 0.146 \\
\hline & $(0.0640)$ & $(0.0623)$ & $(0.189)$ & $(0.114)$ \\
\hline \multirow[t]{2}{*}{ Sul } & $0.257 * * *$ & $0.302^{* * *}$ & 0.185 & $0.284 * *$ \\
\hline & $(0.0681)$ & $(0.0689)$ & $(0.189)$ & $(0.121)$ \\
\hline \multirow[t]{2}{*}{ Centro-Oeste } & $0.186^{* *}$ & $0.308^{* * *}$ & -0.139 & $0.388^{* * *}$ \\
\hline & $(0.0739)$ & $(0.0699)$ & $(0.205)$ & $(0.135)$ \\
\hline Curso matutino & Ref. & Ref. & Ref. & Ref. \\
\hline \multirow{2}{*}{ Curso vespertino } & -0.0451 & 0.0115 & -0.151 & -0.105 \\
\hline & $(0.0648)$ & $(0.0445)$ & $(0.140)$ & $(0.0832)$ \\
\hline \multirow{2}{*}{ Curso noturno } & 0.0371 & $0.0641 * * *$ & 0.0252 & 0.0630 \\
\hline & $(0.0272)$ & $(0.0198)$ & $(0.0973)$ & $(0.0442)$ \\
\hline Público Federal & Ref. & Ref. & Ref. & Ref. \\
\hline \multirow{2}{*}{ Público Estadual } & -0.00941 & -0.0624 & -0.153 & 0.0951 \\
\hline & $(0.124)$ & $(0.142)$ & $(0.169)$ & $(0.235)$ \\
\hline \multirow{2}{*}{ Público Municipal } & 0.0585 & $0.293^{*}$ & 0.337 & $0.807 * * *$ \\
\hline & $(0.133)$ & $(0.154)$ & $(0.289)$ & $(0.227)$ \\
\hline Privada & -0.0310 & 0.130 & 0.213 & $0.386^{* *}$ \\
\hline
\end{tabular}


(0.107)

(0.124)

(0.159)

(0.183)

\begin{tabular}{|c|c|c|c|c|}
\hline IF e CEFET & Ref. & Ref. & Ref. & Ref. \\
\hline \multirow{2}{*}{ Centro Univ./ Faculdade } & $0.457^{* *}$ & 0.105 & 0.0653 & $0.129 *$ \\
\hline & $(0.188)$ & $(0.613)$ & $(0.117)$ & $(0.0672)$ \\
\hline \multirow{2}{*}{ Universidade } & $0.458^{* *}$ & 0.0845 & & \\
\hline & $(0.187)$ & $(0.612)$ & & \\
\hline \multirow{2}{*}{$\%$ Doutores } & $-0.0165^{* * *}$ & $-0.0176^{* * *}$ & $-0.0118^{* * *}$ & $-0.0103^{* * *}$ \\
\hline & $(0.00126)$ & $(0.00144)$ & $(0.00286)$ & $(0.00234)$ \\
\hline \multirow{2}{*}{ Constante } & $-2.036^{* * *}$ & $-1.582 * * *$ & $-1.575^{* * *}$ & $-1.619^{* * *}$ \\
\hline & $(0.186)$ & $(0.609)$ & $(0.306)$ & $(0.214)$ \\
\hline Observações & 114,893 & 96,771 & 7,357 & 22,583 \\
\hline Número de grupos & 1,333 & 824 & 156 & 374 \\
\hline Log-likelihood (g.l.) & $-62,976(27)$ & $-53,519(27)$ & $-3,303.4(26)$ & $-12,412.5(26)$ \\
\hline AIC & $126,006.4$ & $107,092.9$ & $6,658.79$ & $24,877.0$ \\
\hline
\end{tabular}

Erro-padrão entre parêntesis. Significância: $* * * \mathrm{p}<0.01,{ }^{*} \mathrm{p}<0.05,{ }^{*} \mathrm{p}<0.1$

Fonte: Instituto Nacional de Estudos e Pesquisas Anísio Teixeira, 2015.

Submetido: $03 / 05 / 2019$

Aprovado: 26/12/2019 